\title{
Oilseed Lipid Supplements and Fatty Acid Composition of Cow Milk: A Meta-Analysis
}

\author{
F. Glasser, ${ }^{1}$ A. Ferlay, and Y. Chilliard \\ Institut National de la Recherche Agronomique, UR1213 Herbivores, Site de Theix, F-63122 Saint-Genès-Champanelle, France
}

\begin{abstract}
Numerous experiments have studied the use of oilseed supplements in cow diets to alter milk fatty acid (FA) composition, but no quantitative synthesis of these studies is currently available. This article reports a meta-analysis of the response of cow milk FA composition to oilseed lipid supplements from linseed, rapeseed, soybeans, and sunflower seed. First, from a database of 145 oilseed supplementation experiments, we collected the mean FA percentages observed with unsupplemented diets and diets supplemented with the 4 oilseeds given as seeds (after various types of processing), as oils (including Ca salts and amides), or in protected forms. Second, we studied the response of the major milk FA percentages to increasing amounts of supplemental lipids from the 4 oilseeds. Responses were nonsignificant, linear, or quadratic, depending on the FA studied and the supplement. Effects of interfering factors, such as supplement form, forage component of the diet, or lactation stage, were difficult to assess from the available data. Third, we studied the response of the major milk FA percentages to increasing dietary intakes of linoleic or linolenic acids, taken separately. Overall, these results confirm the high plasticity of milk FA composition, with the widest variations being observed in the percentages of medium-chain versus C18 FA, and among the C18 in 18:0, cis-18:1, and trans-18:1. The percentages of the polyunsaturated FA cis-9 cis-12-18:2 and 18:3 were less variable, except when protected lipids (mostly formaldehyde treated) were supplied. However, trans-18:1 and polyunsaturated FA (including conjugated linoleic acid) exhibited the greatest variations when expressed relative to their respective basal values (for unsupplemented diets). Oils, compared with seeds, induced greater percentages of trans-18:1 and tended to decrease C6 to C12 FA more. Intakes of 18:2- and 18:3-rich lipid sources did not differ greatly in their effects on short- and medium-chain
\end{abstract}

Received January 2, 2008

Accepted August 6, 2008.

${ }^{1}$ Corresponding author: fglasser@clermont.inra.fr
FA and trans-18:1 percentages, although the profiles of individual 18:1 and 18:2 isomers in milk differed. This meta-analysis provides quantitative estimates, obtained from the extensive literature produced over more than $40 \mathrm{yr}$, of the impact of oilseed supplements on milk FA composition.

Key words: dairy cow, milk fatty acid, plant oil, oilseed

\section{INTRODUCTION}

Public health concerns are driving research into modifying the fatty acid (FA) profiles of cow's milk, particularly toward less saturated medium-chain FA and more long-chain polyunsaturated FA. The simplest way of altering milk fat composition is to supplement the diets of cows with unsaturated lipids. Over the last $40 \mathrm{yr}$, hundreds of studies and several reviews (e.g., Palmquist et al., 1993; Dewhurst et al., 2006; Chilliard et al., 2007) have been published on the response of milk fat composition to dietary lipid supplements. Some have attempted to make a quantitative synthesis of data and calculate means or responses of milk FA, but the data sets have been very small (22 publications in Hermansen, 1995) or without detailed data on unsupplemented and lipid-supplemented diets (Moate et al., 2007). The main sources of unsaturated lipids are oilseed lipids, among which linseed, rapeseed, soybeans, and sunflower seed are used both on farms and for experimental work. Our aim was to study, from the dietary supplementation experiments published to date, the means and responses of milk FA composition to these supplements, together with their putative modifying factors, by using a meta-analysis approach.

\section{MATERIALS AND METHODS}

\section{Inclusion of Publications}

Among the published experiments on dairy cows involving dietary oilseed lipid supplementation (mainly dietary and some ruminal infusion experiments, but no postruminal infusions), we selected those with oilseed lipid supplements from linseed, rapeseed, soybeans, and 
Table 1. Mean fatty acid composition (mean $\pm \mathrm{SD}$, in $\mathrm{g} / 100 \mathrm{~g}$ of total fatty acids) of the oilseed supplements from the database (all forms included)

\begin{tabular}{|c|c|c|c|c|c|c|c|}
\hline Item & C14:0 & $\mathrm{C} 16: 0$ & C16:1 & C18:0 & C18:1 & C18:2 & $\mathrm{C} 18: 3$ \\
\hline Rapeseed $(\mathrm{n}=24)$ & $0.2 \pm 0.3$ & $4.8 \pm 0.9$ & $0.3 \pm 0.3$ & $2.1 \pm 0.5$ & $60.5 \pm 6.5$ & $20.8 \pm 4.8$ & $9.2 \pm 2.5$ \\
\hline Soybean $(\mathrm{n}=44)$ & $0.1 \pm 0.2$ & $11.4 \pm 1.9$ & $0.1 \pm 0.1$ & $4.1 \pm 0.6$ & $22.3 \pm 2.5$ & $53.5 \pm 3.2$ & $7.0 \pm 1.9$ \\
\hline
\end{tabular}

sunflower seed and excluded oleic sunflower, mixes of several lipid sources, and diets containing fish oils. All the information from these publications was stored in a dedicated Access (Microsoft Corp., Redmond, WA) database for further use. This database comprised 145 experiments, corresponding to 426 experimental treatments (see list of references given in the online data supplement; http://jds.fass.org/content/vol91/ issue12/). The mean FA composition of the 4 oilseeds, obtained from the database, are given in Table 1.

\section{Encoding of Experimental Factors and FA}

Several factors known to have putative effects on milk FA composition were encoded for each experimental treatment. Lipid supplement form was encoded as amides, Ca salts, encapsulated oils (in formaldehydecasein), FFA, formaldehyde-treated seeds, crushed seeds, whole seeds, heat-treated seeds (roasted), extruded seeds, micronized seeds, ground seeds, or triglycerides (oils). These forms were then grouped into 3 categories, designated "protected" lipids (encapsulated oils and formaldehyde-treated seeds), "seeds" (all types of processing included), and "oils" (including Ca salts and amides). A preliminary study had shown fewer differences among forms within each of these 3 categories compared with the between-category differences. Specific comparisons were made within categories when sufficient data were available (see below).

The lactation stage was encoded in 3 classes according the number of DIM at the beginning of the experiment (early lactation for less than 30 DIM, mid lactation for 30 to $150 \mathrm{DIM}$, late lactation for more than 150 DIM). The main forage of the basal diet was also encoded (alfalfa, corn silage, pasture, grass silage, or grass hay).

Because of the heterogeneity among publications in how milk FA were reported, certain data had to be reconciled, especially for some C18 FA. Thus, for cis18:1, trans-18:1, 18:2, 18:3, and conjugated linoleic acid (CLA), the values used were either reported global values or the sums of the corresponding isomers when more detailed FA profiles were provided. For trans $(\boldsymbol{t})$-10- and $t 11-18: 1$, when only one of these isomers (generally t11-18:1) was reported, it was taken as the sum of $t 10+11-18: 1$ given the low resolution of most GC for these 2 isomers. Hence, $t 10$ - and $t 11-18: 1$ values are those for which the 2 isomers were reported.

\section{Strategy of Analysis and Statistical Approaches}

Three strategies of analysis were chosen for the data set. First, the mean milk FA percentages $(\mathrm{g} / 100 \mathrm{~g}$ of total FA) were computed for each combination of lipid source and supplement form (protected, seeds, and oils), and control treatments (unsupplemented). These analyses covered all the available data in the database, and the values obtained were compared by nonparametric ANOVA [NPAR procedure of SAS (SAS Institute Inc, Cary, NC), Kruskall-Wallis test], between control and supplemented diets, and among supplement forms for the same lipid source.

Second, the responses of the main FA to the amounts of supplements were determined. For these analyses, only experiments including a control treatment (unsupplemented) were selected. Although a large number of experiments were in the original database (145), the number rapidly decreased when selection criteria were applied. Several modes of expression of the amount supplemented were compared: dietary intake of lipid or total FA or a given FA, amount of DM or lipid or total FA, or a given FA supplied by the supplement. Among these possibilities, the amount of lipid supplied by the supplement (expressed in grams per day) was the expression that was reported in or could be computed from the largest number of experiments, and so was chosen as an independent variable for the estimation of amount supplemented. There were 106 experiments with supplemental lipid data. For each experiment, we computed the differences between the supplemented treatments and the control treatment, both for the independent variable (amount of lipid supplied by the supplement) and the responses (percentage of selected FA in milk total FA, milk fat content). These data (within-experiment differences) were analyzed with GLM models, forced through the origin (the differ- 
Table 2. Mean percentages of the main fatty acids in milk (expressed as g/100 g of total fatty acids) according to the lipid source (linseed or rapeseed) and form: "seeds" (variously processed), "protected" (i.e., encapsulated or formaldehyde treated), or "oils" (including oils, amides, and Ca salts)

\begin{tabular}{|c|c|c|c|c|c|c|c|}
\hline \multirow[b]{2}{*}{ Variable $^{2}$} & \multirow[b]{2}{*}{ Unsupplemented } & \multicolumn{3}{|c|}{ Linseed } & \multicolumn{3}{|c|}{ Rapeseed } \\
\hline & & Seeds & Protected & Oils & Seeds & Protected & Oils \\
\hline $\begin{array}{l}\text { Supplement } \\
\mathrm{DM}(\mathrm{kg} / \mathrm{d})\end{array}$ & - & $1.87 \pm 0.88(30)$ & $2.25 \pm 0.98(9)$ & $0.63 \pm 0.32(9)$ & $1.54 \pm 0.86(51)$ & $1.36 \pm 0.91(7)$ & $0.65 \pm 0.34(29)$ \\
\hline $\begin{array}{l}\text { Supplement } \\
\text { fat }(g / d)\end{array}$ & - & $649 \pm 204(18)$ & $692 \pm 307(9)$ & $613 \pm 299(10)$ & $679 \pm 457(34)$ & $484 \pm 309(9)$ & $532 \pm 228(31)$ \\
\hline $\begin{array}{l}\text { Supplement lipids } \\
(\% \text { of DMI })\end{array}$ & - & $3.6 \pm 1.2(18)$ & $3.7 \pm 1.9(9)$ & $3.2 \pm 1.7(10)$ & $3.9 \pm 2.7(32)$ & $2.6 \pm 1.5(9)$ & $2.9 \pm 1.3(28)$ \\
\hline $\begin{array}{l}\text { Lipid intake } \\
\text { (\% of DMI) }\end{array}$ & $3.13 \pm 0.83(73)$ & $6.5 \pm 1.7(24)$ & $5.7 \pm 1.3(4)$ & $7.2 \pm 2(6)$ & $5.4 \pm 1.3(26)$ & $6 \pm 1.7(7)$ & $6.6 \pm 1.3(15)$ \\
\hline DMI (kg/d) & $20 \pm 4.2(122)$ & $18.9 \pm 2.5(30)$ & $19.7 \pm 2.1(9)$ & $19.5 \pm 3.1(10)$ & $18.6 \pm 3.3(42)$ & $18.5 \pm 3.1(11)$ & $18.9 \pm 3.8(29)$ \\
\hline Milk yield $(\mathrm{kg} / \mathrm{d})$ & $27.1 \pm 7.9(134)$ & $26.8 \pm 7.8(31)$ & $29.2 \pm 4.3(9)$ & $27.2 \pm 6.4(10)$ & $25.3 \pm 7.3(50)$ & $25.6 \pm 4.2(8)$ & $27.5 \pm 7.4(32)$ \\
\hline Milk fat $(\mathrm{g} / \mathrm{kg})$ & $37.3 \pm 5.6(134)$ & $37.9 \pm 5.4(30)$ & $39.5 \pm 6.5(9)$ & $33 \pm 7.1(10)$ & $36.2 \pm 5.3(49)$ & $38.4 \pm 4.9(8)$ & $36.1 \pm 5.5(31)$ \\
\hline Fat yield (g/d) & $990 \pm 269(133)$ & $1003 \pm 242(30)^{\mathrm{ab}}$ & $1134 \pm 157(9)^{\mathrm{b}}$ & $875 \pm 225(10)^{\mathrm{a}}$ & $920 \pm 250(48)$ & $990 \pm 191(8)$ & $972 \pm 227(32)$ \\
\hline \multicolumn{8}{|l|}{$\begin{array}{l}\text { Fatty acid } \\
\text { (g/100 } \mathrm{g} \text { of total } \\
\text { fatty acids) }\end{array}$} \\
\hline $4: 0$ & $3.3 \pm 1.3(101)$ & $2.58 \pm 0.87(21)$ & $2.2 \pm 1.4(3)$ & $2.9 \pm 1.1(7)$ & $2.86 \pm 0.86(41)^{\mathrm{a}}$ & $2.86 \pm 0.5(8)^{\mathrm{a}}$ & $4 \pm 1.4(24)^{\mathrm{b}}$ \\
\hline $6: 0$ & $2.28 \pm 0.73(114)$ & $1.99 \pm 0.65(24)$ & $1.73 \pm 0.24$ & $1.59 \pm 0.68(8)$ & $2.01 \pm 0.51(46)^{\mathrm{a}}$ & $1.68 \pm 0.58(9)^{\mathrm{a}}$ & $2.53 \pm 0.76(26)^{\mathrm{b}}$ \\
\hline $8: 0$ & $1.42 \pm 0.44(118)$ & $1.16 \pm 0.37(24)$ & $1.06 \pm 0.22$ & $1.06 \pm 0.6(9)$ & $1.21 \pm 0.38(50)$ & $1.11 \pm 0.45$ & $1.32 \pm 0.41(27)$ \\
\hline 10:0 & $3.37 \pm 0.88(124)$ & $2.53 \pm 0.92(29)$ & $2.91 \pm 0.3$ & $2.07 \pm 0.98(9)$ & $2.69 \pm 0.8(52)$ & $2.54 \pm 0.76(12)$ & $2.96 \pm 0.78(28)$ \\
\hline $10: 1$ & $0.27 \pm 0.14$ & - & - & $0.163 \pm 0.041$ & $0.21 \pm 0.1(6)$ & of - & - \\
\hline $11: 0$ & $0.21 \pm 0.17(16)$ & $0.08 \pm 0.053$ & - & $0.066 \pm 0.058(5)$ & $0.28 \pm 0.21(11)$ & - & - \\
\hline $12: 0$ & $4.1 \pm 1(125)$ & $3.1 \pm 1(29)^{b}$ & $3.35 \pm 0.32(4)^{\mathrm{b}}$ & $2.36 \pm 0.89(9)^{a}$ & $3.19 \pm 0.93(52)$ & $3.01 \pm 0.8(12)$ & $3.04 \pm 0.77(29)$ \\
\hline $12: 1$ & $0.128 \pm 0.048$ & - & - & - & $0.114 \pm 0.012$ & - & - \\
\hline $13: 0$ & $0.22 \pm 0.18(16)$ & $0.082 \pm 0.019$ & - & $0.135 \pm 0.052(5)$ & $0.2 \pm 0.14$ & - & - \\
\hline 14:0 & $12.3 \pm 1.9(130)$ & $9.9 \pm 2.2(30)$ & $9.5 \pm 1.2(8)$ & $9.4 \pm 2.5(9)$ & $10.4 \pm 1.6(53)$ & $10.5 \pm 2(12)$ & $10.5 \pm 1.7(29)$ \\
\hline 14:0iso & $1.1 \pm 1.8(6)$ & - & - & $0.078 \pm 0.038$ & $0.87 \pm 0.12(3)$ & -1 & - \\
\hline $14: 1$ & $1.45 \pm 0.59(93)$ & $1.18 \pm 0.69(24)^{\mathrm{b}}$ & $1.22 \pm 0.36(4)^{\mathrm{ab}}$ & $0.8 \pm 0.22(8)^{a}$ & $1.23 \pm 0.56(42)$ & $0.87 \pm 0.29(6)$ & $1.08 \pm 0.3(22)$ \\
\hline $15: 0$ & $1.4 \pm 0.38$ & $1.04 \pm 0.23(24)$ & - & $0.92 \pm 0.18(8)$ & $1.22 \pm 0.25(32)^{\mathrm{b}}$ & $0.93 \pm 0.21(3)^{\mathrm{ab}}$ & $1.05 \pm 0.16(16)^{\mathrm{a}}$ \\
\hline 15:0ante & $0.58 \pm 0.13(8)$ & - & - & $0.53 \pm 0.15$ & $0.492 \pm 0.036(6)$ & -10 & $200-1-1$ \\
\hline 15:0iso & $0.45 \pm 0.38(7)$ & - & - & $0.22 \pm 0.11$ & $0.77 \pm 0.45$ & - & - \\
\hline $16: 0$ & $31.3 \pm 4.7(135)$ & $24.1 \pm 3.9(32)$ & $21.8 \pm 3.2(9)$ & $21.9 \pm 7.4(9)$ & $25 \pm 3.9(53)$ & $24.4 \pm 4.2(12)$ & $25.1 \pm 3.8(32)$ \\
\hline 16:0iso & $0.309 \pm 0.032(6)$ & - & - & $0.205 \pm 0.07$ & $0.323 \pm 0.07(4)$ & - & - \\
\hline $16: 1$ & $2.12 \pm 0.97(114)$ & $1.42 \pm 0.75(29)^{\mathrm{a}}$ & $2.13 \pm 0.44(4)^{\mathrm{b}}$ & $1.48 \pm 0.65(9)^{\mathrm{a}}$ & $1.83 \pm 0.88(48)$ & $2.3 \pm 1.6(11)$ & $1.57 \pm 0.52(29)$ \\
\hline $16: 1 c$ & $1.59 \pm 0.54(26)$ & $1.13 \pm 0.65(11)$ & - & $0.99 \pm 0.61(6)$ & $1.45 \pm 0.41(6)$ & - & $1.08 \pm 0.48(16)$ \\
\hline $16: 1 t$ & $0.5 \pm 0.45(18)$ & $0.22 \pm 0.18(7)$ & - & $0.4 \pm 0.29(6)$ & $0.34 \pm 0.19$ & - & $0.71 \pm 0.34(16)$ \\
\hline $17: 0$ & $0.72 \pm 0.26(71)$ & $0.59 \pm 0.11(20)$ & - & $0.554 \pm 0.051(6)$ & $0.59 \pm 0.22(32)$ & $0.6 \pm 0.21$ & $0.6 \pm 0.11(17)$ \\
\hline 17:0ante & $0.68 \pm 0.24(4)$ & - & - & - & $0.833 \pm 0.064$ & - & - \\
\hline 17:0iso & $0.525 \pm 0.019$ & - & - & - & $0.48 \pm 0.072$ & - & - \\
\hline $17: 1$ & $0.297 \pm 0.086(21)$ & $0.19 \pm 0.034(5)$ & - & $0.192 \pm 0.023(4)$ & $0.224 \pm 0.053(8)$ & - & - \\
\hline Total C18 & $35.4 \pm 6.3(127)$ & $48.2 \pm 7.9(32)$ & $47.6 \pm 4.9(5)$ & $54 \pm 8.5(9)$ & $45.4 \pm 6.9(52)$ & $49.1 \pm 8.5(12)$ & $47.5 \pm 6.6(31)$ \\
\hline 18:0 & $9.7 \pm 2.3(136)$ & $14.4 \pm 3.1(32)$ & $14.3 \pm 4(5)$ & $11.9 \pm 2.6(9)$ & $13.1 \pm 2.1(53)$ & $12.2 \pm 4.7(12)$ & $13.6 \pm 2.2(32)$ \\
\hline Total 18:1 & $22 \pm 4.2(140)$ & $29.2 \pm 5.4(33)^{b}$ & $25.3 \pm 3.6(9)^{\mathrm{a}}$ & $33.2 \pm 6.2(9)^{\mathrm{b}}$ & $29 \pm 5.1(53)$ & $31.7 \pm 5.7(12)$ & $30.8 \pm 5.6(32)$ \\
\hline cis- $18: 1$ & $19.8 \pm 3.8(80)$ & $26.8 \pm 5(28)^{\mathrm{b}}$ & $22.4 \pm 2.9(7)^{\mathrm{a}}$ & $23.6 \pm 5.6(6)^{\mathrm{ab}}$ & $25.2 \pm 6(19)$ & $28.3 \pm 6.3(4)$ & $26.9 \pm 4.4(27)$ \\
\hline trans-18:1 & $2.1 \pm 1.2(81)$ & $3.1 \pm 1.9(26)^{\mathrm{a}}$ & $2.56 \pm 0.72(8)^{\mathrm{a}}$ & $10.3 \pm 4.2(7)^{\mathrm{b}}$ & $2.22 \pm 0.79(18)^{\mathrm{a}}$ & $2.32 \pm 1(4)^{\mathrm{a}}$ & $4.1 \pm 1.7(29)^{\mathrm{b}}$ \\
\hline Total 18:2 & $2.9 \pm 1.3(134)$ & $3.3 \pm 1.1(32)^{a}$ & $3.7 \pm 1.8(9)^{\mathrm{ab}}$ & $8.1 \pm 5.7(9)^{b}$ & $2.7 \pm 1.2(53)^{\mathrm{a}}$ & $3.74 \pm 0.88(12)^{\mathrm{b}}$ & $2.8 \pm 1(32)^{\mathrm{a}^{\prime}}$ \\
\hline Total 18:3 & $0.67 \pm 0.49(121)$ & $1.11 \pm 0.35(33)^{\mathrm{a}}$ & $2.4 \pm 1.7(9)^{b}$ & $0.85 \pm 0.51(9)^{\mathrm{a}}$ & $0.65 \pm 0.22(50)^{\mathrm{a}}$ & $1.42 \pm 0.77(12)^{\mathrm{b}}$ & $0.58 \pm 0.29(31)^{\mathrm{a}}$ \\
\hline$c 6 c 9 c 12$ & $0.12 \pm 0.1(10)$ & $0.069 \pm 0.064$ & & & & - & \\
\hline$c 9 c 12 c 15$ & $0.59 \pm 0.26(40)$ & $1.06 \pm 0.4(19)^{a}$ & $1.56 \pm 0.41(7)^{\mathrm{b}}$ & $0.91 \pm 0.45(7)^{\mathrm{a}}$ & $0.63 \pm 0.31$ & - & $0.56 \pm 0.18(8)$ \\
\hline 19:0 & $0.25 \pm 0.14(6)$ & - & - & $0.136 \pm 0.023(3)$ & $0.473 \pm 0.058$ & - & - \\
\hline
\end{tabular}


ence in FA percentage was, by definition, zero when the supplement was at zero). Models including linear and quadratic effects of supplemental lipid were tested, together with interactions with supplement form (i.e., different slopes according to the supplement form) when there were at least 3 data points per supplement form. The significance level was set at $P=0.05$. This withinexperiment approach enabled us to exclude experiment effects (linked to various unknown effects such as location or genetic factors) and focus on the dietary effect of the supplement. All the experiments did not report the same milk FA. We thus studied the responses for the main FA reported in the literature (i.e., FA with more than 10 data points for at least 3 of the 4 lipid sources). In addition, we summed some FA (C6 to C8, C10 to C14) to simplify the expression of results.

We then carried out complementary analyses on putative interfering factors on the previously obtained models of milk FA percentages according to supplemental lipid. Three types of complementary analysis were conducted: 1) comparisons of different supplement forms within the pooled categories (seeds, protected, oils), 2) effects of lactation stage (early, mid, and late lactation) on the model coefficients, and 3) effects of the forage component of the basal ration (encoded according to the main forage of the diet) on the adjusted models. As for the mean responses (see above), the analyses were performed separately for each type of supplement (i.e., lipid source $\times$ form), or pooled for each lipid source if there was no effect of supplement form within lipid source. In each case, we selected the subsets of data that included more than 3 data points for each class of interfering factor.

Third, in another complementary approach, we determined the response of selected FA percentages to the dietary intakes of 18:2n-6 and 18:3n-3, with all lipid sources being pooled (to have sufficient data). To study the specific effect of 18:2n-6, we selected publications with a substantial within-experiment variation in 18:2 intake (greater than $100 \mathrm{~g} / \mathrm{d}$ ) and a relatively small variation in 18:3 intake (less than $30 \%$ of the variation in 18:2), and reciprocally for the specific effect of 18:3n3 . These thresholds were chosen from the distribution of the variations in the data set to limit interfering effects between the $2 \mathrm{FA}$ and at the same time to have sufficient data. Data (milk FA percentages) were analyzed with mixed models (St-Pierre, 2001), including a random experiment effect and the total intake of $18: 2 \mathrm{n}$ 6 or 18:3n-3, expressed in grams per day. The form of the supplement was also introduced in the models as an interaction with FA intake to test its significance, but was not taken into account in the resulting equations if not significant $(P \geq 0.05)$. 
Table 3. Mean percentages of the main FA in milk (expressed as $\mathrm{g} / 100 \mathrm{~g}$ of total fatty acids) according to the lipid source (soybean or sunflower seed) and form: "seeds" (variously processed), "protected" (i.e., encapsulated or formaldehyde treated) or "oils" (including oils, amides, and Ca salts)

\begin{tabular}{|c|c|c|c|c|c|c|c|}
\hline \multirow[b]{2}{*}{ Variable $^{2}$} & \multirow[b]{2}{*}{ Unsupplemented } & \multicolumn{3}{|c|}{ Soybean } & \multicolumn{3}{|c|}{ Sunflower seed } \\
\hline & & Seeds & Protected & Oils & Seeds & Protected & Oils \\
\hline Supplement DM (kg/d) & - & $2.9 \pm 1.3(47)$ & $3.5 \pm 3.2(7)$ & $0.53 \pm 0.2(33)$ & $1.69 \pm 0.57(17)$ & $1.5 \pm 1.2(8)$ & $0.67 \pm 0.26(9)$ \\
\hline Supplement fat (g/d) & - & $557 \pm 277(28)$ & $868 \pm 505(10)$ & $533 \pm 228(38)$ & $798 \pm 239(9)$ & $697 \pm 410(8)$ & $651 \pm 293(7)$ \\
\hline Supplement lipids (\% of DMI) & - & $3.2 \pm 1.3(24)$ & $4.3 \pm 2.1(9)$ & $2.9 \pm 1.2(33)$ & $3.8 \pm 1.1(9)$ & $4.5 \pm 1.9(8)$ & $3.7 \pm 1.5(6)$ \\
\hline Lipid intake (\% of DMI) & $3.13 \pm 0.83(73)$ & $5.43 \pm 0.68(25)$ & - & $5.71 \pm 0.65(17)$ & $5.75 \pm 0.95(17)$ & $8.1 \pm 1.8(4)$ & $5.4 \pm 2.1(4)$ \\
\hline DMI $(\mathrm{kg} / \mathrm{d})$ & $20 \pm 4.2(122)$ & $19.4 \pm 4.2(41)$ & $19 \pm 6(9)$ & $19.3 \pm 5.2(37)$ & $20.3 \pm 3.6(18)^{\mathrm{b}}$ & $14.7 \pm 4.2(8)^{\mathrm{a}}$ & $19.7 \pm 4.1(8)^{\mathrm{b}}$ \\
\hline Milk yield $(\mathrm{kg} / \mathrm{d})$ & $27.1 \pm 7.9(134)$ & $28 \pm 8.4(49)$ & $24 \pm 10(10)$ & $27.3 \pm 8.5(42)$ & $30.7 \pm 7.6(18)^{\mathrm{c}}$ & $17.1 \pm 3.6(8)^{a}$ & $25 \pm 4.5(9)^{\mathrm{b}}$ \\
\hline Fat content $(\mathrm{g} / \mathrm{kg})$ & $37.3 \pm 5.6(134)$ & $34 \pm 5.6(49)^{\mathrm{a}}$ & $39.8 \pm 8.6(10)^{\mathrm{b}}$ & $34.4 \pm 5.9(43)^{\mathrm{a}}$ & $32.3 \pm 5.1(18)^{\mathrm{a}}$ & $44.9 \pm 4.4(8)^{\mathrm{b}}$ & $29.8 \pm 7.4(9)^{\mathrm{a}}$ \\
\hline Fat yield $(\mathrm{g} / \mathrm{d})$ & $990 \pm 269(133)$ & $945 \pm 278(49)$ & $948 \pm 407(10)$ & $944 \pm 331(42)$ & $975 \pm 248(18)^{b}$ & $759 \pm 156(8)^{\mathrm{a}}$ & $735 \pm 177(9)^{\mathrm{a}}$ \\
\hline \multicolumn{8}{|l|}{$\begin{array}{l}\text { Fatty acid (g/100 g } \\
\text { of total fatty acids) }\end{array}$} \\
\hline 4:0 & $3.3 \pm 1.3(101)$ & $3.8 \pm 1.5(41)$ & $3.5 \pm 1.1(6)$ & $3.2 \pm 1.3(35)$ & $2.5 \pm 1.6(10)^{\mathrm{a}}$ & $5.43 \pm 0.15(3)^{\mathrm{b}}$ & $1.8 \pm 1.9(4)^{\mathrm{a}}$ \\
\hline $6: 0$ & $2.28 \pm 0.73(114)$ & $2.3 \pm 0.64(42)^{\mathrm{b}}$ & $1.99 \pm 0.58(7)^{\mathrm{ab}}$ & $1.85 \pm 0.68(34)^{\mathrm{a}}$ & $1.6 \pm 1.1(16)^{\mathrm{a}}$ & $2.71 \pm 0.62(7)^{\mathrm{b}}$ & $1.17 \pm 0.61(7)^{a}$ \\
\hline $8: 0$ & $1.42 \pm 0.44(118)$ & $1.28 \pm 0.39(43)^{\mathrm{b}}$ & $1.12 \pm 0.28(7)^{\mathrm{ab}}$ & $0.98 \pm 0.4(35)^{a}$ & $0.94 \pm 0.46(16)^{\mathrm{a}}$ & $1.61 \pm 0.35(7)^{\mathrm{b}}$ & $0.89 \pm 0.59(8)^{\mathrm{a}}$ \\
\hline 10:0 & $3.37 \pm 0.88(124)$ & $2.73 \pm 0.68(45)^{\mathrm{b}}$ & $2.72 \pm 0.64(9)^{b}$ & $2.17 \pm 0.72(36)^{\mathrm{a}}$ & $2.31 \pm 0.59(18)^{b}$ & $2.83 \pm 0.84(8)^{\mathrm{b}}$ & $1.82 \pm 0.9(8)^{a}$ \\
\hline $10: 1$ & $0.27 \pm 0.14$ & $0.079 \pm 0.058$ & - & - & - & - & - \\
\hline 11:0 & $0.21 \pm 0.17(16)$ & $0.038 \pm 0.027(5)^{\mathrm{a}}$ & - & $0.126 \pm 0.068(7)^{\mathrm{b}}$ & - & - & - \\
\hline $12: 0$ & $4.1 \pm 1(125)$ & $3.05 \pm 0.64(45)^{\mathrm{b}}$ & $3.07 \pm 0.65(9)^{b}$ & $2.56 \pm 0.74(36)^{\mathrm{a}}$ & $2.85 \pm 0.8(18)$ & $2.68 \pm 0.81(8)$ & $2.24 \pm 0.92(8)$ \\
\hline $12: 1$ & $0.128 \pm 0.048(7)$ & $0.056 \pm 0.062(3)$ & - & - & - & - & - \\
\hline $13: 0$ & $0.22 \pm 0.18(16)$ & $0.09 \pm 0.029(5)$ & - & $0.4 \pm 0.24$ & - & - & - \\
\hline $14: 0$ & $12.3 \pm 1.9(130)$ & $9.8 \pm 1.6(46)$ & $9.9 \pm 1.8(10)$ & $9.3 \pm 2(36)$ & $9.8 \pm 1.3(18)$ & $8.4 \pm 1.6(8)$ & $9.4 \pm 2.4(9)$ \\
\hline 14:0iso & $1.1 \pm 1.8(6)$ & - & - & - & - & & \\
\hline $14: 1$ & $1.45 \pm 0.59(93)$ & $1.07 \pm 0.33(39)$ & $1.19 \pm 0.47(7)$ & $0.92 \pm 0.4(30)$ & $1.14 \pm 0.39(15)^{\mathrm{b}}$ & $0.67 \pm 0.12(5)^{\mathrm{a}}$ & $1.22 \pm 0.44(6)^{\mathrm{b}}$ \\
\hline $15: 0$ & $1.4 \pm 0.38$ & $1.16 \pm 0.36(22)^{\mathrm{b}}$ & - & $0.81 \pm 0.12(21)^{\mathrm{a}}$ & $0.96 \pm 0.25(8)$ & - & $1.06 \pm 0.5(5)$ \\
\hline 15:0ante & $0.58 \pm 0.13(8)$ & - & - & - & - & - & - \\
\hline 15:0iso & $0.45 \pm 0.38(7)$ & - & - & - & - & - & - \\
\hline 16:0 & $31.3 \pm 4.7(135)$ & $23.7 \pm 4.1(49)$ & $24.6 \pm 4.2(10)$ & $26 \pm 4.7(38)$ & $24.3 \pm 3.9(18)$ & $20.7 \pm 6.4(8)$ & $22.4 \pm 5.5(9)$ \\
\hline 16:0iso & $0.309 \pm 0.032(6)$ & - & - & & & & \\
\hline $16: 1$ & $2.12 \pm 0.97(114)$ & $1.79 \pm 0.63(43)$ & $1.8 \pm 1(7)$ & $1.6 \pm 0.52(35)$ & $1.9 \pm 1(14)^{\mathrm{a}}$ & $1.06 \pm 0.12(5)^{\mathrm{a}}$ & $2.05 \pm 0.6(9)^{\mathrm{b}}$ \\
\hline $16: 1 c$ & $1.59 \pm 0.54(26)$ & $1.19 \pm 0.12(8)$ & - & $1.18 \pm 0.33(3)$ & $1.26 \pm 0.21(3)$ & - & - \\
\hline $16: 1 t$ & $0.5 \pm 0.45$ & $0.54 \pm 0.2(7)$ & - & - & $0.161 \pm 0.071$ & - & - \\
\hline $17: 0$ & $0.72 \pm 0.26(71)$ & $0.69 \pm 0.29(21)^{\mathrm{b}}$ & - & $0.56 \pm 0.11(12)$ & $0.52 \pm 0.14$ & - & $0.69 \pm 0.41(4)$ \\
\hline 17:0ante & $0.68 \pm 0.24$ & - & - & - & - & - & - \\
\hline 17:0iso & $0.525 \pm 0.019$ & - & - & - & - & - & - \\
\hline $17: 1$ & $0.297 \pm 0.086(21)$ & $0.253 \pm 0.063(6)$ & - & $0.213 \pm 0.025(3)$ & $0.35 \pm 0.11(4)^{\mathrm{b}}$ & - & $0.207 \pm 0.021(3)^{\mathrm{a}}$ \\
\hline Total C18 & $35.4 \pm 6.3(127)$ & $48 \pm 6.8(44)$ & $50.9 \pm 7.8(9)$ & $48.5 \pm 6.8(40)$ & $53.3 \pm 8.4(12)$ & $58.5 \pm 9.1(8)$ & $55 \pm 9.4(7)$ \\
\hline $18: 0$ & $9.7 \pm 2.3(136)$ & $12.9 \pm 2.3(48)$ & $14.2 \pm 2.6(10)$ & $13.6 \pm 2.7(42)$ & $14 \pm 3.5(18)$ & $15.4 \pm 4.7(8)$ & $12.2 \pm 2.3(9)$ \\
\hline Total 18:1 & $22 \pm 4.2(140)$ & $28.6 \pm 5.1(49)^{\mathrm{ab}}$ & $25.5 \pm 5.5(10)^{\mathrm{a}}$ & $30.1 \pm 5.9(42)^{\mathrm{b}}$ & $34.9 \pm 5.6(18)^{\mathrm{b}}$ & $26.6 \pm 6.1(8)^{\mathrm{a}}$ & $36.8 \pm 6.9(9)^{\mathrm{b}}$ \\
\hline Cis-18:1 & $19.8 \pm 3.8(80)$ & $22.9 \pm 2.9(25)$ & $23.7 \pm 4.6(3)$ & $24.5 \pm 3.2(24)$ & $28.5 \pm 5(10)$ & - & $25.7 \pm 4.4(5)$ \\
\hline Trans-18:1 & $2.1 \pm 1.2(81)$ & $4.9 \pm 3.2(24)$ & $4.4 \pm 2.6(3)$ & $5.9 \pm 2.6(25)$ & $5.8 \pm 2.4(9)^{\mathrm{a}}$ & - & $10.8 \pm 4.6(5)^{\mathrm{b}}$ \\
\hline Total 18:2 & $2.9 \pm 1.3(134)$ & $5.1 \pm 1.8(47)^{\mathrm{b}}$ & $9.6 \pm 3.4(8)^{c}$ & $4 \pm 1.7(35)^{a}$ & $3.7 \pm 1.4(18)^{\mathrm{a}}$ & $15.3 \pm 8.6(8)^{\mathrm{b}}$ & $5.3 \pm 2.9(9)^{\mathrm{a}}$ \\
\hline Total 18:3 & $0.67 \pm 0.49(121)$ & $0.94 \pm 0.53(40)^{\mathrm{b}}$ & $1.82 \pm 0.81(7)^{c}$ & $0.77 \pm 0.55(30)^{\mathrm{a}}$ & $0.68 \pm 0.9(12)^{\mathrm{a}}$ & $1.25 \pm 0.54(8)^{b}$ & $1.0 \pm 1.3(7)^{\mathrm{ab}}$ \\
\hline$c 6 c 9 c 12$ & $0.12 \pm 0.1(10)$ & $0.18 \pm 0.18(6)$ & - & & & - & \\
\hline$c 9 c 12 c 15$ & $0.59 \pm 0.26(40)$ & $0.72 \pm 0.18(11)^{\mathrm{b}}$ & - & $0.44 \pm 0.14(11)^{\mathrm{a}}$ & $0.53 \pm 0.22(6)$ & - & $0.54 \pm 0.13(4)$ \\
\hline 19:0 & $0.25 \pm 0.14(6)$ & - & - & $0.352 \pm 0.073(5)$ & - & - & - \\
\hline $20: 0$ & $0.25 \pm 0.2(42)$ & $0.31 \pm 0.29(14)$ & $0.63 \pm 0.25$ (4) & $0.36 \pm 0.5(12)$ & $0.68 \pm 0.88$ & - & $0.148 \pm 0.044$ \\
\hline $20: 1$ & $0.15 \pm 0.11(24)$ & $0.14 \pm 0.14(7)$ & - & $0.153 \pm 0.049$ & $0.151 \pm 0.039$ & - & - \\
\hline $20: 2$ & $0.076 \pm 0.075$ & $0.082 \pm 0.078$ & - & - & - & - & - \\
\hline $20: 2 \mathrm{n}-6$ & $0.067 \pm 0.087(5)$ & - & - & - & - & - & - \\
\hline $20: 3$ & $0.13 \pm 0.04(17)$ & $0.132 \pm 0.034(7)$ & - & - & $0.091 \pm 0.043$ & - & - \\
\hline
\end{tabular}




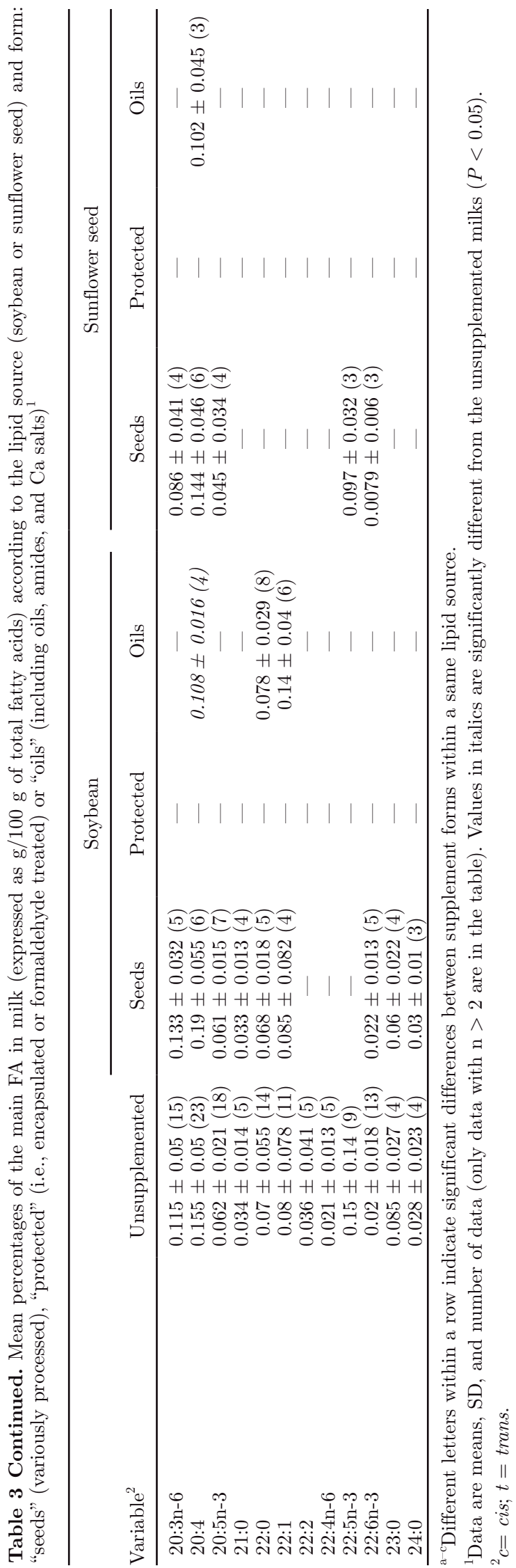

\section{RESULTS}

\section{Mean Composition of Milk FA with Unsupplemented and Lipid-Supplemented Diets}

The mean amounts of supplemental lipids ranged between 484 and $868 \mathrm{~g} / \mathrm{d}$ (Table 2 and Table 3), and there was no significant difference among supplements. Data for DMI, milk yield, milk fat content, and milk fat yield are given for their order of magnitude, but because of the wide variability between experiments, linked to the production levels of the cows or other experimental effects, they are not directly comparable between columns. In particular, 7 of the 8 values for protected sunflower seeds came from 2 publications (Bartsch et al., 1976; Clapperton, 1982) with very low production levels, and thus were not comparable with the mean of the unsupplemented diets.

The mean values of milk FA percentages (expressed in $\mathrm{g} / 100 \mathrm{~g}$ of total FA) for the unsupplemented diets and the various supplements (according to lipid source and form of the supplement) are given in Table 2 and Table 3. Milk 4:0 was affected little by lipid supplements and was even increased by rapeseed oils, soybean seeds, and protected sunflower seed. Milk 6:0 to 10:0 were decreased by all supplements except protected sunflower seed. Protected linseed diets were not significantly different from the control diets $(P=0.08$ to 0.15$)$ for these FA, but this was probably due to the low number of data values $(\mathrm{n}=3)$. Otherwise, their numerical values were very similar to all the other supplements. The protection of linseed, rapeseed, and soybeans did not prevent the decrease of 6:0 to 10:0 compared with unprotected forms, and oils induced a greater decrease than seeds, especially for soybeans and sunflower seed. The medium-chain FA 12:0, 14:0, 15:0, and 16:0 were decreased by all the supplements, with 12:0 being more strongly affected by oils than by the other 2 forms. For 14:0 and 16:0, the supplement form did not affect the extent of the decrease, which was also similar between lipid sources. The 14:1, 16:1, 17:0, and 17:1 were also decreased by most supplements, but trans-16:1 was not affected, unlike cis-16:1. Very few data were available for branched-chain FA, and their percentages were not greatly modified by lipid supplements in the database.

The percentages of total C18, 18:0, and total 18:1 were increased by all supplements. Mean percentage of total $\mathrm{C} 18$ with unsupplemented diets was $35 \%$, and this increased to 45 to $59 \%$ with lipid-supplemented diets. The mean values were similar for linseed, rapeseed, and soybeans, and were somewhat greater with sunflower seed. There was no significant effect of supplement form, within lipid source, on the percentages of total C18 or 18:0. Trans-18:1 was increased by all the supplements except rapeseed given as seeds or protected. For all lipid 
sources, the increase in trans-18:1 was more pronounced with oils compared with seeds or protected lipids. The greatest values were observed for linseed and sunflower seed oils (approximately 10\% of total FA). When the individual percentages of cis- and trans-18:1 isomers were studied (Table 4), we found that cis (c)-9-18:1 was increased by all the supplements except linseed oils and sunflower seed oils (the latter finding was probably not significant because of the small number of data, but was numerically greater than the unsupplemented diets). Linseed oils increased almost all the 18:1 isomers, whereas seeds had a weaker effect. For the other lipid sources, fewer data were available, and no clear pattern emerged, except that t9-18:1 and $t 10+11-18: 1$ were increased by almost all the supplements.

Total 18:2 was increased by linseed seeds and oils, protected rapeseed (Table 2), and all forms of soybeans and sunflower seed (Table 3). Detailed profiles (Table 4) revealed that total CLA and c9t11-CLA were significantly increased by all supplements, except rapeseed as seeds and oils, for which only a numerical increase was observed. Data on the other CLA isomers were too scant to draw conclusions. The $c 9 c 12-18: 2$ isomer was increased by soybeans and sunflower seed as seeds, from 2.4 (unsupplemented) to 3 to $4 \%$ of total FA, but was not significantly affected by linseed or rapeseed. Data on the other nonconjugated isomers were very scant, and the only significant increases were for $c 9 t 13-$ and t11c15-18:2 with linseed oils.

Increases in 18:3 percentages were observed with all the protected supplements and with linseed and soybean seeds. Protected supplements induced greater values ( 1.25 to $2.40 \%$ of total FA) compared with the other forms, and mean values ranked linseed $\geq$ soybean $\geq$ rapeseed $\geq$ sunflower seed. Compared with $0.67 \%$ of total FA with unsupplemented diets, unprotected supplements did not exceed a mean of $1.10 \%$ of total FA (even if values as great as $4 \%$ were reported in some early experiments, values for 18:3 with unprotected supplements did not exceed $2 \%$ in recent experiments with detailed milk FA profiles).

Percentages of FA with 20 carbons or more were weakly affected by lipid supplements, except for a decrease in 20:3 and 20:4 percentages with linseed seeds and oils, a decrease in 20:4 also with rapeseed and soybean oils, and a decrease in $22: 5 n-3$ and increase in 22:6n-3 with linseed oils.

\section{Within-Experiment Responses of Milk FA Composition to the Amount of Lipid Supplement}

The relationships between amount of lipid supplied by the supplements and the variations in milk FA percentages are presented in Table 5. Intercepts were set at zero because the within-experiment variations were defined in relation to the unsupplemented diets, for which the amount of supplement is zero and the variation is, by definition, also zero. These relationships between amount of lipid supplied by the supplements and the variations in milk FA percentages were most often significant (Table 5), except for 4:0, which was affected (and then to a limited extent) only by linseed supplements. Percentages of $\mathrm{C} 6$ to $\mathrm{C} 8$ were linearly decreased by linseed as seeds and more largely as oils, as well as sunflower seed, rapeseed, and soybeans (all forms). Percentage of C10 to C14 decreased linearly or quadratically according to lipid source, but the effect was not significantly different within lipid source among supplement forms, except for linseed, for which oils were more inhibitory. In addition, the models obtained were very close among lipid sources for moderate amounts of supplemental lipids (i.e., less than 800 to $900 \mathrm{~g} / \mathrm{d}$ ), corresponding to a decrease of 4.5 to $5.8 \mathrm{~g}$ of C10 to C14 per $100 \mathrm{~g}$ of total milk FA for $600 \mathrm{~g}$ of supplemental lipid (the mean amount across all supplements), irrespective of lipid source. Quadratic and linear models differed mainly for very large quantities of supplemental lipids $(>1 \mathrm{~kg} / \mathrm{d})$.

The percentage of 16:0 decreased quadratically with supplemental lipid for all lipid sources. Only linseed and sunflower seed showed significant differences between supplement forms. The modeled decrease in 16:0 percentage corresponding to $600 \mathrm{~g}$ of supplemental lipids lay between -5.7 and $-10.1 \%$ of total FA, with protected linseed (the smallest decrease) $\geq$ sunflower seed oils $\cong$ soybean (all forms) $\geq$ linseed as seeds $\geq$ sunflower seed as seeds $\geq$ rapeseed (all forms) $\geq$ linseed oils. The modeled decrease for protected sunflower seed reached $-12.9 \%$ of total FA.

Models of increases in total C18 percentage were quadratic (Table 5), with significant effects of supplement forms for linseed and sunflower seed, symmetrical to what was observed for 16:0. For $600 \mathrm{~g}$ of supplemental lipid, the modeled percentage of total C18 increased by 11.5 to $20.9 \%$ of total FA, in the order protected linseed $\leq$ sunflower seed oils $\leq$ soybean (all forms) $\cong$ rapeseed (all forms) $\cong$ linseed as seeds $\leq$ sunflower seed as seeds $\leq$ linseed oils $\leq$ protected sunflower seed. However, rapeseed and sunflower seed increased total C18 percentage up to more than $1 \mathrm{~kg}$ of supplemental lipids, whereas linseed and soybeans reached a maximum percentage of C18 with 600 to $850 \mathrm{~g}$ of supplemental lipids and decreased thereafter.

Models for 18:0 corresponded to increases of 3.6 to 5.6 $\%$ in total FA for $600 \mathrm{~g}$ of supplemental lipids, except for sunflower seed oils, with no significant dose-dependent increase. All supplements induced a steady increase in 18:0 percentage with increasing supplemental lipids. 
Table 4. Mean percentages of selected C18 isomers in milk (expressed as $\mathrm{g} / 100 \mathrm{~g}$ of total fatty acids) according to the lipid source and form: "protected" (i.e., encapsulated or formaldehyde treated), "seeds" (variously processed), or "oils" (including oils, amides, and Ca salts)"

$\begin{array}{ll}\text { Item }^{2} & \text { Unsupplemented }\end{array}$

\begin{aligned} & \hline Protected \\ & $22.3 \pm \\ &=2.8(7)^{\mathrm{ab}} \\ &- \\ &- \\ &- \\ &- \\ &- \\ &- \\ & 2.54 \pm \\ &-63(5)^{\mathrm{a}} \\ &- \\ &- \\ &-\end{aligned}$

Linseed

Rapeseed

$0.41 \pm 0.064(5)$

$19 \pm 3.5(50)$

$c 9$

$c 11$

$c 12$
$c 13$

$c 14+t 16$

$c 15$

t4

t5

$t 6+7+8$

$t 6+7+8$
$t 9$

t10

$t 10+11$

$t 11$

$t 13+14$

$t 15$

$\stackrel{t 16}{\text { Conjugated 18:2 }}$

$\begin{array}{lr}\text { Total } & 0.67 \\ c 9 c 11 & 0.023(52) \\ c 9 t 11 & 0.026(4)\end{array}$

$c 9 c 11$

$c 9 t 11$

t9t11

$t 10 c 12$

$t 11 t 13$

Nonconjugated 18:2

$0.62 \pm 0.38(29)$

$0.37 \pm 0.16(10)$

$0.28 \pm 0.1$ (3)

$0.153 \pm 0.077(6)$

$0.0174 \pm 0.0092(4)$

$0.0173 \pm 0.0092(4)$

$0.152 \pm 0.033(5)$

$0.283 \pm 0.097(10)$

$\begin{aligned} 0.27 & \pm 0.2(19) \\ 0.6 & \pm 0.48(12)\end{aligned}$

$\begin{aligned} 0.6 & \pm 0.48(12) \\ 1.78 & \pm 0.87(40)\end{aligned}$

$1.7 \pm 1.1(12)$

$0.37 \pm 0.25$ (10)

$0.61 \pm 0.22(8)$

$0.22 \pm 0.13(3)$

$\begin{aligned} 0.023 & \pm 0.026(4) \\ 0.58 & \pm 0.29(32)\end{aligned}$

$0.035 \pm 0.019(5)$

$0.025 \pm 0.05(14)$

Seeds

Oils

$25.7 \pm 5.5(23)^{\mathrm{b}}$

$0.48 \pm 0.16(14)$

$0.286 \pm 0.067(5)^{\mathrm{a}}$
$0.088 \pm 0.047(4)^{\mathrm{a}}$

$0.6 \pm 0.24$ (4)

$0.018 \pm 0.01(3)$

$c 9 c 12$

$2.39 \pm 0.88(52)$

c $9 t 12$

$\begin{aligned} 0.13 & \pm 0.1(5) \\ 0.054 & \pm 0.049(4)\end{aligned}$

t9c12

$0.13 \pm 0.12(10)$

c9t13

$0.217 \pm 0.075(3)$

$t 11 c 15$

$0.28 \pm 0.17(6)$

$1.1 \pm 0.37(7)^{\mathrm{a}}$

$\begin{array}{rrr} & 1.0 \pm 0.4(21)^{\mathrm{a}} \\ - & 0.79 & \pm 0.25(14)^{\mathrm{a}} \\ - & 0.0197 & \pm 0.0058(3) \\ - & 0.144 \pm 0.098(3) \\ - & 0.0113 \pm 0.0071(3)\end{array}$

$1.89 \pm 0.52(7)$

$0.0113 \pm 0.0071(3)$

$0.28 \pm 0.2(5)^{\mathrm{a}}$

$0.83 \pm 0.68(10)$

$1.4 \pm 1.2(4)$

$2.3 \pm 1.3(18)$
$35 \pm 0.94(4)$

$0.46 \pm 0.26(5)^{\mathrm{a}}$

$1.25 \pm 0.9(4)^{\mathrm{a}}$

$$
\text { - }
$$

$2.23 \pm 0.66(23)$

$0.22 \pm 0.096(3)$

$0.028 \pm 0.04(3)$

$\begin{array}{cc}- & 0.22 \pm 0.096(3) \\ - & 0.028 \pm 0.04(3) \\ - & -\end{array}$

$0.46 \pm 0.14(6)$

$1.5 \pm 1.2(6)$
$5.9 \pm 2.9(7)^{\mathrm{b}}$

$3.8 \pm 2.1(6)$

$0.87 \pm 0.2(5)^{\mathrm{b}}$

$2.7 \pm 1.2(5)^{\mathrm{b}}$

$0.87 \pm 0.36(4)$

$0.87 \pm 0.36(4)$

$1.94 \pm 0.85(8)^{\mathrm{b}}$

$0.043 \pm 0.029$ (4)

$1.75 \pm 0.84(7)^{b}$

$0.018 \pm 0.016(5)$

$0.079 \pm 0.062(4)$

$2.05 \pm 0.59(7)$

$0.243 \pm 0.028(3)$

$0.174 \pm 0.089(3$

$0.117 \pm 0.078$ (4)

$0.96 \pm 0.48$ (4)

\begin{tabular}{ll}
\multicolumn{2}{c}{ Rapeseed } \\
\hline Seeds & Oils \\
\hline
\end{tabular}

$\begin{array}{cc}25.4 \pm \overline{7.2(11)} & 25.1 \pm \overline{3.4}(16) \\ 0.5 \pm 0.17(7)^{\mathrm{a}} & 1.09 \pm 0.34(9)^{\mathrm{b}} \\ - & - \\ - & - \\ - & - \\ - & - \\ - & - \\ - & -\end{array}$

$2.02 \pm \overline{0.59}(5)^{\mathrm{a}}$

$0.35 \pm 0.1$ (4)

-

$4.1 \pm \overline{2.1}(16)^{\mathrm{b}}$

-

-

-

$0.88 \pm 0.54(11)$

$1 \pm 0.5$ (18)

$0.68 \pm 0.44(5)$

$0.72 \pm 0.37$ (11)

-

-

$2 \pm 1(13)$

$2.12 \pm 0.74(12)$

-

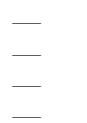

Continued 
Table 4 Continued. Mean percentages of selected C18 isomers in milk (expressed as g/100 g of total fatty acids) according to the lipid source and form: "protected" (i.e., encapsulated or formaldehyde treated), "seeds" (variously processed), or "oils" (including oils, amides, and Ca salts)

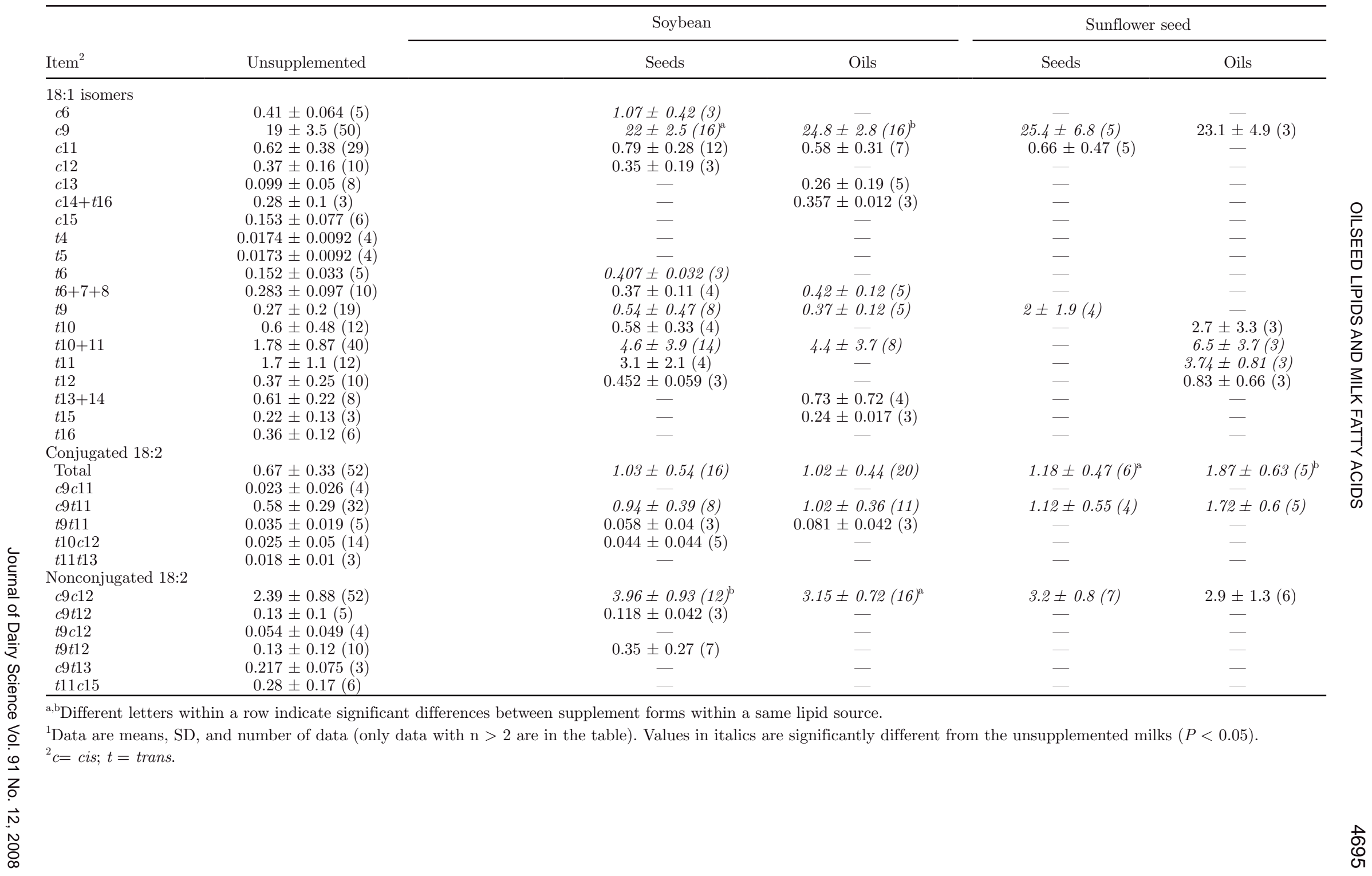


Percentages of cis- and trans-18:1 increased linearly with increasing supplemental lipids, with this increase sometimes differing between supplement forms. For these FA, coefficients for protected rapeseed and sunflower seed (Table 5) are given for the record but are not representative because they were obtained for only one experiment. For cis-18:1, rapeseed and linseed as seeds had the greatest coefficients (corresponding to +7 $\mathrm{g} / 100 \mathrm{~g}$ of total FA of cis-18:1 for $600 \mathrm{~g}$ of supplemental lipid), followed by sunflower seed as seeds, soybean and linseed oils, and then sunflower seed oils and protected linseed. Percentage of trans-18:1 was linearly increased most by linseed oils, followed by soybean oils, sunflower seed, rapeseed oils, and linseed as seeds. None of the other supplements significantly increased trans-18:1 percentage according to the amount supplemented.

Soybean seeds induced the main dose-dependent increase in $c 9 c 12-18: 2$ percentage, followed by soybean oils and sunflower seed (all forms). Rapeseed had only a marginal effect (seeds), or even decreased $c 9 c 12-18: 2$ percentages at high doses (oils), whereas linseed had no significant effect.

Total CLA percentage was linearly increased by all supplements except rapeseed as seeds (coefficient for protected rapeseed is given for the record, based on one experiment), mostly by soybeans, followed by sunflower seed, rapeseed oils, and linseed.

For the percentage of $18: 3$, one experiment with protected flaxseed (Goodridge et al., 2001) reported extremely large increases $(+3$ and $+5 \%$ of total FA), and was excluded from the data set used for model adjustment. All other experiments with linseed supplements reported increases of no more than $1 \%$ of total FA, with a maximum around $600 \mathrm{~g}$ of supplemental lipids and decreasing thereafter. Similar increases were reported with protected rapeseed and even greater increases $(+2 \%)$ with different forms of soybeans. Rapeseed as seeds only marginally increased 18:3 percentage, whereas rapeseed oils and sunflower seed had no significant effect (or even decreased 18:3 percentage, with some protected sunflower seed supplements strongly increasing $c 9 c 12-18: 2$ ).

Milk fat content was linearly decreased by all supplements given as oils and by rapeseed and sunflower as seeds. The strong increase observed with protected sunflower seed was based on 2 experiments (Bartsch et al., 1976; Clapperton, 1982).

\section{Examination of Putative Interfering Factors in Responses to Lipid Supplements}

Three types of interfering factors were studied on the previously obtained models: 1) the effect of supplement form within the 3 supplement form categories (pro- tected, seeds, and oils), 2) the main forage of the basal diet, and 3) lactation stage. The criteria set for the minimum number of data $(\mathrm{n}=3)$ for each factor class drastically reduced the number of possible analyses.

Concerning the effect of supplement form, we compared, within linseed seeds, the effects of extruded or micronized seeds, whole seeds, and ground seeds. There was a significant effect on the response of several FA: linseed lipids given as extruded, micronized, or ground seeds decreased $\mathrm{C} 6$ to $\mathrm{C} 8, \mathrm{C} 10$ to $\mathrm{C} 14$, and 16:0 percentages, and increased total C18, trans-18:1, CLA, and 18:3 percentages more than did whole seeds. For $18: 3$ percentage, the slopes were $1.32,0.89$, and 0.43 (in percentage of total FA per kilogram of supplemental lipid) for ground seeds, extruded or micronized seeds, and whole seeds, respectively. For rapeseed as seeds, no significant difference was found in the response of any FA percentages in milk between whole or crushed seeds, roasted seeds, or ground seeds. For rapeseed oils, we compared oils and Ca salts of rapeseed FA. A significant difference was found only in the cis-18:1 percentage: Ca salts increased milk cis-18:1 by $14.2 \pm 1.2 \%$ of total FA per kilogram of supplemental lipid, compared with 10.5 $\pm 1.1 \%$ for oils. Three other comparisons were made: 1) extruded versus roasted soybeans (within soybean seeds), 2) encapsulated soybean oil versus formaldehyde-treated soybeans (within protected soybeans) and 3) soybean Ca salts versus soybean oil (within soybean oils). In none of these cases was the response of milk FA percentages found to differ between supplement forms.

Concerning the effect of the main forage component of the diet on the response to linseed supplements (all types of supplements pooled), we found an effect only for the response of milk cis-18:1 percentage, with the greatest increase being observed with alfalfa-based diets $(\mathrm{n}=2)$, followed by corn silage, grass hay, and then grass silage. On the response to rapeseed supplements (all supplements pooled), there was a significant effect of the main forage on the linear coefficient of the response of $\mathrm{C} 10$ to $\mathrm{C} 14$, total $\mathrm{C} 18,18: 0$, and trans-18:1 (see models in Table 5). For C10 to C14 percentage, the decrease was maximal with grass silage and corn silage diets, followed by alfalfa, grass hay, and then pasture. The increase in total C18 percentage showed an inverse pattern (maximal increase with grass silage and corn silage). Percentage of 18:0 increased less and trans-18:1 percentage increased more with pasture diets compared with all other forages, but in each case the significant effect was due to a single experiment (respectively, Nowak and Potkanski, 2000; Fearon et al., 2004). Otherwise, there was no significant effect of forage type on the response of other FA to rapeseed supplements. For soybeans, the results were similar when all supplements were pooled or if only soybean oils were considered. 
Table 5. Within-experiment variations of milk fatty acid percentages (in $\mathrm{g} / 100 \mathrm{~g}$ of total fatty acids) according to the amount of lipid supplied by supplement (X in $\mathrm{kg} / \mathrm{d}$; for unsupplemented diets, $\mathrm{X}=0$ and the variation $=0)^{1}$

\begin{tabular}{|c|c|c|c|c|}
\hline Lipid source & Linseed & Rapeseed & Soybean & Sunflower seed \\
\hline $\begin{array}{l}\text { Supplement lipid }(\mathrm{X}, \mathrm{kg} / \mathrm{d}) \\
\mathrm{C} 4: 0\end{array}$ & $\begin{array}{l}0.65( \pm 0.04)[0.19-1.12] \\
-0.34( \pm 0.14) \mathrm{X} \\
n=20, R M S E=0.41, R^{2}=0.23\end{array}$ & $\begin{array}{l}0.59( \pm 0.36)[0.05-1.97] \\
\text { NS }\end{array}$ & $\begin{array}{l}0.59( \pm 0.31)[0.05-1.68] \\
\text { NS }\end{array}$ & $\begin{array}{l}0.72( \pm 0.31)[0.18-1.28] \\
\text { NS }\end{array}$ \\
\hline C6 to $\mathrm{C} 8$ & $\begin{array}{l}\text { S: }-0.74( \pm 0.18) \mathrm{X} \\
\text { P: }-0.4( \pm 0.7, \mathrm{NS}) \mathrm{X} \\
\mathrm{O}:-2.12( \pm 0.29) \mathrm{X} \\
n=23, R M S E=0.45, R^{2}=0.78\end{array}$ & $n=59, R M S E=0.46, R^{2}=0.26$ & $-1.05( \pm 0.18) \mathrm{X}$ & $n=18, R M S E=0.72, R^{2}=0.47$ \\
\hline C10 to $\mathrm{C} 14$ & $\begin{array}{l}\text { S: }-8.2( \pm 0.7) \mathrm{X} \\
\mathrm{P}:-6.3( \pm 2.7) \mathrm{X} \\
\mathrm{O}:-12.2( \pm 1.1) \mathrm{X} \\
n=23, R M S E=1.72, R^{2}=0.93\end{array}$ & $-9.1( \pm 0.7) \mathrm{X}+2.5( \pm 0.6) \mathrm{X}^{2}$ & $-14.8( \pm 1.3) \mathrm{X}+8.6( \pm 1.5) \mathrm{X}^{2}$ & $-10.0( \pm 0.5) \mathrm{X}$ \\
\hline C16:0 & $\begin{array}{l}\text { S: }-21.3( \pm 3.2) \mathrm{X}+13.5( \pm 3.9) \mathrm{X}^{2} \\
\mathrm{P}:-17.6( \pm 3.8) \mathrm{X}+13.5( \pm 3.9) \mathrm{X}^{2} \\
\mathrm{O}:-24.9( \pm 3.4) \mathrm{X}+13.5( \pm 3.9) \mathrm{X}^{2} \\
n=30, R M S E=3.0, R^{2}=0.88\end{array}$ & $-18.9( \pm 1.3) \mathrm{X}+6.7( \pm 1.1) \mathrm{X}^{2}$ & $\begin{array}{l}-15.2( \pm 1.5) \mathrm{X}+4.7( \pm 1.4) \mathrm{X}^{2} \\
n=55, R M S E=2.9, R^{2}=0.85\end{array}$ & $\begin{array}{l}n=17, R M D E=1.3, \kappa=0.90 \\
\mathrm{~S}:-22.3( \pm 2.5) \mathrm{X}+12.9( \pm 2.7) \mathrm{X}^{2} \\
\mathrm{P}:-29.3( \pm 2.8) \mathrm{X}+12.9( \pm 2.7) \mathrm{X}^{2} \\
\mathrm{O}:-20.1( \pm 2.4) \mathrm{X}+12.9( \pm 2.7) \mathrm{X}^{2} \\
n=19, R M S E=2.0, R^{2}=0.97\end{array}$ \\
\hline Total C18 & $\begin{array}{l}\text { S: } 37.1( \pm 5.3) \mathrm{X}-21.3( \pm 6.8) \mathrm{X}^{2} \\
\mathrm{P}: 32.0( \pm 5.8) \mathrm{X}-21.3( \pm 6.8) \mathrm{X}^{2} \\
\mathrm{O}: 46.2( \pm 5.5) \mathrm{X}-21.3( \pm 6.8) \mathrm{X}^{2} \\
n=26, R M S E=4.1, R^{2}=0.94\end{array}$ & $30( \pm 1.7) X-9.6( \pm 1.5) X^{2}$ & $\begin{array}{l}36.9( \pm 4.1) \mathrm{X}-21.3( \pm 5.9) \mathrm{X}^{2} \\
n=54, R M S E=4.8, R^{2}=0.87\end{array}$ & $\begin{array}{l}\text { S: } 37.8( \pm 4.7) \mathrm{X}-18.2( \pm 5.9) \mathrm{X}^{2} \\
\mathrm{P}: 45.8( \pm 5.9) \mathrm{X}-18.2( \pm 5.9) \mathrm{X}^{2} \\
\mathrm{O}: 33.4( \pm 4.7) \mathrm{X}-18.2( \pm 5.9) \mathrm{X}^{2} \\
n=18, R M S E=3.6, R^{2}=0.97\end{array}$ \\
\hline C18:0 & $6.9( \pm 0.6) \mathrm{X}$ & $9.2( \pm 0.7) \mathrm{X}-3.1( \pm 0.6) \mathrm{X}^{2}$ & $8.9( \pm 1.1) \mathrm{X}$ & $\begin{array}{l}\text { S: } 6.4( \pm 0.8) \mathrm{X} \\
\text { P: } 9.3( \pm 0.9) \mathrm{X} \\
\text { O: } 4.0( \pm 1.5, \mathrm{NS}) \mathrm{X}\end{array}$ \\
\hline Cis-18:1 & $\begin{array}{l}n=26, R M S E=2.1, R^{2}=0.82 \\
\text { S: } 11.4( \pm 1.3) \mathrm{X} \\
\mathrm{P}: 3.4( \pm 1.4) \mathrm{X} \\
\mathrm{O}: 8.6( \pm 1.9) \mathrm{X} \\
n=22, R M S E=2.9, R^{2}=0.84\end{array}$ & $\begin{array}{l}n=73, R M S E=1.8, R^{2}=0.85 \\
12.0( \pm 0.6) \mathrm{X}\end{array}$ & $\begin{array}{l}n=60, R M S E=2.4, R^{2}=0.75 \\
8.8( \pm 1.4) \mathrm{X} \\
n=28, R M S E=3.4, R^{2}=0.61\end{array}$ & $\begin{array}{l}n=19, R M S E=1.7, R^{2}=0.92 \\
\text { S: } 9.8( \pm 1.3) \mathrm{X} \\
\text { P: }-9.4( \pm 4.8, \mathrm{NS}) \mathrm{X} \\
\mathrm{O}: 5.1( \pm 2.2) \mathrm{X} \\
n=11, R M S E=2.4, R^{2}=0.90\end{array}$ \\
\hline Trans-18:1 & $\begin{array}{l}\text { S: } 2.4( \pm 0.9) \mathrm{X} \\
\text { P: } 1.0( \pm 0.9, \mathrm{NS}) \mathrm{X} \\
\mathrm{O}: 10.6( \pm 1.2) \mathrm{X} \\
n=24, R M S E=1.8, R^{2}=0.81\end{array}$ & $\begin{array}{l}\text { S: } 0.4( \pm 0.5, \mathrm{NS}) \mathrm{X} \\
\text { P: } 2.3( \pm 2.7, \mathrm{NS}) \mathrm{X} \\
\mathrm{O}: 4.5( \pm 0.5) \mathrm{X} \\
n=37, R M S E=1.4, R^{2}=0.73\end{array}$ & $\begin{array}{l}\text { S: } 2.0( \pm 1.5, \mathrm{NS}) \mathrm{X} \\
\text { P: } 1.7( \pm 2.7, \mathrm{NS}) \mathrm{X} \\
\mathrm{O}: 7.9( \pm 0.9) \mathrm{X} \\
n=29, R M S E=1.9, R^{2}=0.75\end{array}$ & $6.5( \pm 1.7) \mathrm{X}$ \\
\hline Cis-9 cis-12-18:2 & NS & $\begin{array}{l}\text { S: } 0.24( \pm 0.09) \mathrm{X} \\
\mathrm{O}: 0.9( \pm 0.3) \mathrm{X}-1.4( \pm 0.4) \mathrm{X}^{2} \\
n=18, R M S E=0.18, R^{2}=0.66\end{array}$ & $\begin{array}{l}\text { S: } 2.89( \pm 0.27) \mathrm{X} \\
\mathrm{O}: 1.06( \pm 0.25) \mathrm{X} \\
n=14, R M S E=0.30, R^{2}=0.92\end{array}$ & $n=7, R M S E=0.4, R^{2}=0.53$ \\
\hline Total conjugated linoleic acid & $0.67( \pm 0.18) \mathrm{X}$ & $\begin{array}{l}\text { S: } 0.12( \pm 0.09, \mathrm{NS}) \mathrm{X} \\
\text { P: } 1.29( \pm 0.46) \mathrm{X} \\
\text { O: } 0.67( \pm 0.1) \mathrm{X}\end{array}$ & $1.36( \pm 0.24) X$ & $1.15( \pm 0.32) \mathrm{X}$ \\
\hline $\mathrm{C} 18: 3$ & $\begin{array}{l}n=25, R M S E=0.62, R^{2}=0.37 \\
\text { S: } 1.8( \pm 0.3) \mathrm{X}-1.5( \pm 0.4) \mathrm{X}^{2} \\
\text { P: } 2.0( \pm 0.4) \mathrm{X}-1.5( \pm 0.4) \mathrm{X}^{2} \\
\mathrm{O}: 1.4( \pm 0.3) \mathrm{X}-1.5( \pm 0.4) \mathrm{X}^{2} \\
n=28, R M S E=0.3, R^{2}=0.79\end{array}$ & $\begin{array}{l}n=23, R M S E=0.24, R^{2}=0.74 \\
\text { S: } 0.13( \pm 0.05) \mathrm{X} \\
\text { P: } 0.91( \pm 0.12) \mathrm{X} \\
\text { O: } 0.08( \pm 0.07, \mathrm{NS}) \mathrm{X} \\
n=69, R M S E=0.21, R^{2}=0.48\end{array}$ & $\begin{array}{l}n=16, R M S E=0.43, R^{2}=0.68 \\
0.50( \pm 0.07) \mathrm{X}\end{array}$ & $\begin{array}{l}n=5, R M S E=0.45, R^{2}=0.76 \\
\mathrm{~S}:-0.05( \pm 0.3, \mathrm{NS}) \mathrm{X} \\
\mathrm{P}:-1.66( \pm 0.3) \mathrm{X} \\
\mathrm{O}:-0.23( \pm 0.51, \mathrm{NS}) \mathrm{X} \\
n=18, R M S E=0.56, R^{2}=0.67\end{array}$ \\
\hline Milk fat $(\mathrm{g} / \mathrm{kg})$ & $\begin{array}{l}\text { S: } 0.7( \pm 1.0, \mathrm{NS}) \mathrm{X} \\
\text { P: } 1.4( \pm 1.3, \mathrm{NS}) \mathrm{X} \\
\mathrm{O}:-5.3( \pm 1.7) \mathrm{X} \\
n=30, R M S E=0.3, R^{2}=0.29\end{array}$ & $\begin{array}{l}\text { S: }-3.3( \pm 0.7) \mathrm{X} \\
\mathrm{P}:-0.1( \pm 0.2, \mathrm{NS}) \mathrm{X} \\
\mathrm{O}:-5.5( \pm 1.0) \mathrm{X} \\
n=69, R M S E=0.3, R^{2}=0.45\end{array}$ & $\begin{array}{l}\text { S: } 0.5( \pm 1.5, \mathrm{NS}) \mathrm{X} \\
\mathrm{P}: 1.5( \pm 1.3, \mathrm{NS}) \mathrm{X} \\
\mathrm{O}:-6.8( \pm 1.1) \mathrm{X} \\
n=61, R M S E=0.4, R^{2}=0.39\end{array}$ & $\begin{array}{l}\text { S: }-4.0( \pm 1.4) \mathrm{X} \\
\mathrm{P}: 17.3( \pm 1.6) \mathrm{X} \\
\mathrm{O}:-5.2( \pm 2.7) \mathrm{X} \\
n=19, R M S E=0.3, R^{2}=0.89\end{array}$ \\
\hline
\end{tabular}

${ }^{1}$ When there was a significant effect of the supplement form $(P<0.05)$, the corresponding models are provided for each form $(\mathrm{S}=$ "seeds"; $\mathrm{P}=$ "protected"; $\mathrm{O}=$ "oils"); otherwise, a single model is provided, valid for all forms. The mean, SE, and range of lipids brought by the supplements are given for each lipid source. Model coefficients are \pm SE. NS indicate nonsignificant coefficients $(P>0.05)$. 
However, the ranking of the various forages varied according to the milk FA studied: for $\mathrm{C} 10$ to $\mathrm{C} 14$ and 16:0, the greatest decreases were observed with grass hay-based diets. For total C18, 18:0, and trans-18:1, the greatest increases after soybean supplementation were obtained with grass silage and grass hay, and the least with corn silage and alfalfa. For sunflower seed supplements, because of an interaction between supplement form and dietary forage (most grass silage diets were supplemented with protected supplements), no unequivocal effect of forage on the response to the supplements was discerned.

Lactation stage effects were complex, and no global trend could be discerned concerning the interaction between lactation stage and response to the supplements. Depending on the supplement or supplement form studied, and on the FA studied, there were significant or nonsignificant effects of the lactation stage on the response of milk FA percentages to the supplement, and even for the same FA, the lactation stages did not rank identically for the various supplements. Given this complexity, which somewhat restricted the use of these relationships, we opted not to present the results in detail.

\section{Response of Milk FA Percentages to Intakes of 18:2 and 18:3}

The data used for model adjustments were selected to determine specific effects of each of these 2 FA. Among experiments increasing dietary 18:2 intake, we selected those with an increase in 18:3 intake representing less than $30 \%$ of the 18:2 increase, and inversely for experiments increasing 18:3 intake. On the resulting models, we checked that there were no significant effects of the other FA.

The adjusted models of the effects of $18: 2$ and $18: 3$ intakes on the percentages of the main $\mathrm{FA}$ are given in Table 6 . The 2 data sets were similar for the mean FA intake (370 and $301 \mathrm{~g} / \mathrm{d}$, respectively, for 18:2 and 18:3) but differed somewhat in range (reaching 941 vs. $577 \mathrm{~g} / \mathrm{d}$, respectively). Some responses to 18:2 intake included a quadratic component, with an extremum between 700 and $800 \mathrm{~g}$ of intake. We could thus compare the variations induced by either $18: 2$ or $18: 3$ in a range from 0 to $600 \mathrm{~g}$ of intake. All models adjusted for 18:3 intake were linear in this range of intake, except that of trans-18:1.

Percentages of 4:0 were not significantly affected by $18: 2$, and only slightly by 18:3 intake (Table 6 ). Percentages of $\mathrm{C} 6$ to $\mathrm{C} 8$ were slightly but significantly reduced by both $18: 2$ and 18:3 intakes. Up to $600 \mathrm{~g} / \mathrm{d}$, 18:3 fed as oils and 18:2 had similar effects, which were more pronounced than 18:3 fed as seeds or protected.
Similarly, for C10 to C14, the decrease induced by $18: 2$ was similar to that induced by 18:3 supplied as oils, but 18:3 supplied as seeds or protected induced a smaller decrease. Intake of 18:2 decreased 16:0 percentage more than did 18:3 intake.

For total C18, the pattern was opposite that of $\mathrm{C} 10$ to C14: there was a similar increase by $18: 2$ and $18: 3$ supplied as oils, whereas 18:3 supplied as seeds induced a smaller increase. Percentages of 18:0 increased more in response to $18: 2$ intake than to $18: 3$ intake. The responses of total cis-18:1 and total trans-18:1 were somewhat greater for 18:3 than for 18:2. Percentage of total 18:2 was also significantly increased by $18: 3$ intake, but probably from 18:2 isomers other than $c 9 c 12$ 18:2 (nonsignificant effect of 18:3 intake), including CLA (significant effect of 18:3 intake), and probably other nonconjugated trans isomers (Chilliard et al., 2007). Intake of 18:3 also significantly increased 18:3 percentage in milk FA, corresponding to $+0.4 \%$ of $18: 3$ in milk total FA for an intake of $300 \mathrm{~g} / \mathrm{d}$. Percentage of total 18:2 was significantly increased by 18:2 intake only when supplied in a protected form. The response of $c 9 c 12-18: 2$ percentage was significant only for 18:2 as seeds, not as oil (an atypical datum with $21 \%$ of $c 9 c 12$ 18:2 in milk total FA was excluded; Clapperton, 1982). Total CLA response to 18:2 intake was not significant, but was based on 3 experiments only. There was no effect of 18:2 intake on milk 18:3 percentage. Milk fat content was significantly but slightly decreased by $18: 2$ intake as seeds or oil, but was not significantly affected by protected $18: 2$ or 18:3 intake.

\section{DISCUSSION}

\section{Metadesign of Published Data and Methodological Consequences}

The results of a very large number of experiments on dietary lipid supplementation in dairy cows have been published in the last $40 \mathrm{yr}$. Applying the selection criteria of lipid source, selecting only linseed, rapeseed, soybeans, and sunflower seed (thus leaving out animal fats, cottonseed, safflower, fish oils, and mixtures of several lipid sources, among others), we collected 145 experiments. However, the number of available data decreased markedly as soon as one or more additional selection criteria were used, such as FA intake, amount of lipid added to the diet, or data on a given milk FA. We sought to take into account the form of the supplement, which is known to have an influence on the resulting milk FA profiles through the extent of rumen biohydrogenation (Palmquist et al., 1993; Chilliard et al., 2007), but we had to pool several supplement forms to obtain a sufficient number of data, after a 
Table 6. Milk fatty acid percentages (in $\mathrm{g} / 100 \mathrm{~g}$ of total fatty acids) according to 18:2 and 18:3 intakes (from a selection of publications with low variations in the intakes of other fatty $\left.\operatorname{acids}^{1}\right)^{2}$

\begin{tabular}{|c|c|c|}
\hline Item & $18: 2$ & $18: 3$ \\
\hline $\begin{array}{l}\text { Fatty acid intake }(\mathrm{X}, \mathrm{g} / \mathrm{d}) \\
\text { Milk fatty acid }\end{array}$ & $370( \pm 30)[28-941]$ & $301( \pm 41)[18-577]$ \\
\hline $\mathrm{C} 4: 0$ & $\begin{array}{l}3.68( \pm 0.39)-0.000005( \pm 0.0003, \mathrm{NS}) \mathrm{X} \\
\text { Nexp }=12, \text { Ntrt }=34, R M S E=0.3\end{array}$ & $\begin{array}{l}3.22( \pm 0.37)-0.0011( \pm 0.0005) \mathrm{X} \\
\text { Nexp }=5, \text { Ntrt }=17, \text { RMSE }=0.34\end{array}$ \\
\hline $\mathrm{C} 6$ to $\mathrm{C} 8$ & $\begin{array}{l}5.1( \pm 0.3)-0.0051( \pm 0.0011) \mathrm{X}+0.000003( \pm 0.000001) \mathrm{X}^{2} \\
N \exp =15, \text { Ntrt }=41, R M S E=0.4\end{array}$ & $\begin{array}{l}\text { S: } 4.02( \pm 0.30)-0.0022( \pm 0.0005) \mathrm{X} \\
\mathrm{P}: 4.02( \pm 0.30)-0.0021( \pm 0.0012, \mathrm{NS}) \mathrm{X} \\
\mathrm{O}: 4.02( \pm 0.30)-0.0039( \pm 0.0005) \mathrm{X} \\
\text { Nexp }=6, \text { Ntrt }=19, R M S E=0.30\end{array}$ \\
\hline $\mathrm{C} 10$ to $\mathrm{C} 14$ & $\begin{array}{l}27.2( \pm 1.3)-0.036( \pm 0.005) \mathrm{X}+0.000022( \pm 0.000006) \mathrm{X}^{2} \\
\text { Nexp }=15, \text { Ntrt }=40, \text { RMSE }=1.6\end{array}$ & $\begin{array}{l}\text { S: } 21.5( \pm 1.1)-0.0153( \pm 0.0014) \mathrm{X} \\
\mathrm{P}: 4.02( \pm 0.30)-0.0122( \pm 0.0031) \mathrm{X} \\
\mathrm{O}: 21.5( \pm 0.6)-0.0224( \pm 0.0014) \mathrm{X} \\
\text { Nexp }=6, \text { Ntrt }=19, \text { RMSE }=0.8\end{array}$ \\
\hline $\mathrm{C} 16: 0$ & $\begin{array}{l}38.2( \pm 1.6)-0.056( \pm 0.006) \mathrm{X}+0.000041( \pm 0.000007) \mathrm{X}^{2} \\
\text { Nexp }=17, \text { Ntrt }=45, \text { RMSE }=2.4\end{array}$ & $\begin{array}{l}33.1( \pm 2.2)-0.0238( \pm 0.0026) \mathrm{X} \\
\text { Nexp }=7, \text { Ntrt }=21, \text { RMSE }=1.9\end{array}$ \\
\hline Total C18 & $\begin{array}{l}22.0( \pm 2.9)+0.101( \pm 0.010) \mathrm{X}-0.000070( \pm 0.000012) \mathrm{X}^{2} \\
\text { Nexp }=16, \text { Ntrt }=44, \text { RMSE }=3.6\end{array}$ & $\begin{array}{l}\text { S: } 32.4( \pm 2.2)+0.042( \pm 0.004) \mathrm{X} \\
\text { P: } 32.4( \pm 2.2)+0.036( \pm 0.010) \mathrm{X} \\
\text { O: } 32.4( \pm 2.2)+0.057( \pm 0.004) \mathrm{X} \\
\text { Nexp }=7, \text { Ntrt }=21, \text { RMSE }=2.6\end{array}$ \\
\hline C18:0 & $\begin{array}{l}6.3( \pm 0.9)+0.025( \pm 0.004) \mathrm{X}-0.000020( \pm 0.000004) \mathrm{X}^{2} \\
\text { Nexp }=18, \text { Ntrt }=49, \text { RMSE }=1.4\end{array}$ & $\begin{array}{l}9.3( \pm 1.3)+0.0114( \pm 0.0026) \mathrm{X} \\
\text { Nexp }=7, \text { Ntrt }=21, \text { RMSE }=1.9\end{array}$ \\
\hline Cis-18:1 & $\begin{array}{l}20.1( \pm 2.3)+0.013( \pm 0.005) \mathrm{X} \\
\text { Nexp }=8, \text { Ntrt }=20, R M S E=4.8\end{array}$ & $\begin{array}{l}18.3( \pm 1.9)+0.018( \pm 0.004) \mathrm{X} \\
\text { Nexp }=4, \text { Ntrt }=15, R M S E=2.7\end{array}$ \\
\hline Trans-18:1 & $\begin{array}{l}2.2( \pm 1.4, \mathrm{NS})+0.007( \pm 0.003) \mathrm{X} \\
\text { Nexp }=9, \text { Ntrt }=22, \text { RMSE }=3.0\end{array}$ & $\begin{array}{l}1.8( \pm 1.0, \mathrm{NS})+0.000021( \pm 0.000005) \mathrm{X}^{2} \\
\text { Nexp }=6, \text { Ntrt }=19, \text { RMSE }=2.0\end{array}$ \\
\hline C18:2 total & $\begin{array}{l}\mathrm{S}: 2.1( \pm 1.0, \mathrm{NS})+0.0043( \pm 0.0022, \mathrm{NS}) \mathrm{X} \\
\mathrm{P}: 2.1( \pm 1.0, \mathrm{NS})+0.0202( \pm 0.0031) \mathrm{X} \\
\mathrm{O}: 2.1( \pm 1.0, \mathrm{NS})+0.0028( \pm 0.0025, \mathrm{NS}) \mathrm{X} \\
\text { Nexp }=16, \text { Ntrt }=43, R M S E=2.3\end{array}$ & $\begin{array}{l}2.4( \pm 1.4, \mathrm{NS})+0.0068( \pm 0.0032) \mathrm{X} \\
N \exp =7, \text { Ntrt }=21, R M S E=2.3\end{array}$ \\
\hline Cis-9 cis-12-18:2 & $\begin{array}{l}\text { S: } 2.4( \pm 0.7)+0.0042( \pm 0.0008) \mathrm{X} \\
\mathrm{O}: 2.4( \pm 0.7)+0.0009( \pm 0.0004, \mathrm{NS}) \mathrm{X} \\
\text { Nexp }=4, \text { Ntrt }=9,^{3} \text { RMSE }=0.2\end{array}$ & $\begin{array}{l}2.18( \pm 0.30)-0.0002( \pm 0.0007, \mathrm{NS}) \mathrm{X} \\
\text { Nexp }=5, \text { Ntrt }=15, R M S E=0.47\end{array}$ \\
\hline Total conjugated linoleic acid & $\begin{array}{l}0.87( \pm 0.33)+0.00042( \pm 0.00020, \mathrm{NS}) \mathrm{X} \\
\text { Nexp }=3, \text { Ntrt }=6, R M S E=0.11\end{array}$ & $\begin{array}{l}0.70( \pm 0.13)+0.0015( \pm 0.0006) \mathrm{X} \\
\text { Nexp }=6, \text { Ntrt }=19, \text { RMSE }=0.47\end{array}$ \\
\hline $\mathrm{C} 18: 3$ & $\begin{array}{l}0.67( \pm 0.30)+0.00064( \pm 0.00039, \mathrm{NS}) \mathrm{X} \\
\text { Nexp }=13, \text { Ntrt }=35, \text { RMSE }=0.40\end{array}$ & $\begin{array}{l}0.53( \pm 0.13)+0.00119( \pm 0.00035) \mathrm{X} \\
\text { Nexp }=7, \text { Ntrt }=21, \text { RMSE }=0.27\end{array}$ \\
\hline Milk fat content ( $\mathrm{g} / \mathrm{kg}$ of milk) & $\begin{array}{l}\text { S: } 38.1( \pm 1.8)-0.0080( \pm 0.0030) \mathrm{X} \\
\mathrm{P}: 38.1( \pm 1.8)+0.0039( \pm 0.0045, \mathrm{NS}) \mathrm{X} \\
\mathrm{O}: 38.1( \pm 1.8)-0.0099( \pm 0.0037) \mathrm{X} \\
\text { Nexp }=18, \text { Ntrt }=49, \text { RMSE }=3.1\end{array}$ & $\begin{array}{l}38.1( \pm 3.0)-0.0040( \pm 0.0059, \text { NS }) \mathrm{X} \\
N \exp =6, \text { Ntrt }=19, \text { RMSE }=4.3\end{array}$ \\
\hline
\end{tabular}

\section{${ }^{1}$ See text for details.}

(the number of experiments and experimental treatments used are indicated for each model. When there was a significant effect of the supplement form $(P<0.05)$, the corresponding models are given for each form ( $\mathrm{S}=$ "seeds," $\mathrm{P}=$ "protected," O = "oils"); otherwise, a single model is given, valid for all forms. 
preliminary study to identify the main differences. The study of other factors such as forage type or lactation stage was possible only on subsets of data and not for all supplements. Meta-analysis is useful for synthesizing the results of several studies on the same subject, but the statistical method requires a minimum number of data points. The analysis of only a few experiments on the same subject could be done in a standard review not requiring the meta-analysis approach. The use and comparison of published data would be improved in the future if authors reported complete data for FA intakes, amounts of supplements fed, FA content and composition of diets and supplements, and milk FA isomers.

An interexperiment approach was first chosen. This maximizes usable data but has a low discriminating power, and so probably produces some false-negative results. The mean values in each table cell were not obtained from the same data subset, which can sometimes produce odd results. However, the mean amounts of lipids added for the different supplements across all studies were comparable and probably limited the interference of supplement amount in the comparison of the different supplements. Moreover, if cow genetics have a great effect on yields, their milk FA composition is not greatly affected (Bobe et al., 2007).

For the study of responses to the amount of supplement and interfering factors, we studied the effects of factors on the within-experiment differences. Finally, in the study of the response to specific FA intakes, we also chose a within-experiment approach: the experiment effect was taken into account in the statistical model, and among the selected experiments, there was no experiment effect on the independent variables (intakes of 18:2n-6 and 18:3n-3, $P>0.05)$.

\section{Effect of Lipid Supplements on Milk FA Composition}

The response of milk FA composition integrates both rumen metabolism (hydrolysis, isomerization, and biohydrogenation of dietary FA, determining duodenal FA flow and composition) and cow metabolism (lipid mobilization, mammary uptake of plasma FA, mammary de novo synthesis of FA; Chilliard et al., 2000, 2007). Lipid supplementation induces a general increase in C18 percentage at the expense of the short- and medium-chain FA, resulting from an increase in mammary uptake of long-chain FA absorbed in the intestine and a decrease in mammary de novo synthesis (Palmquist et al., 1993). The magnitude of the regression coefficients differed greatly among FA (Table 5). The comparison of these coefficients with the mean value of the corresponding FA in milk from unsupplemented cows shows that, generally speaking, C4 to $\mathrm{C} 8 \mathrm{FA}$ were affected little by the supplements, unlike polyunsaturated FA and, above all, trans-18:1, for which variations relative to basal concentrations were greater.

Short- and Medium-Chain FA. Butyrate percentage in milk FA was not significantly affected by most lipid supplements, although a slight decrease was observed with linseed and sometimes an increase with other lipid supplements. This limited response may originate in its synthesis from BHBA, which is less susceptible to inhibition by long-chain FA, and because some BHBA may arise from FA oxidation. In almost all cases, the decrease in milk short- and medium-chain FA percentage was the result of a decreased secretion of short- and medium-chain FA and an increased secretion of $\mathrm{C} 18$ in milk. All FA from C6 to C16 were decreased by almost all supplements, in accordance with the inhibiting role of several trans $\mathrm{C} 18$ isomers produced in the rumen on de novo FA synthesis (Bauman and Griinari, 2001; Shingfield and Griinari, 2007) and maybe directly by dietary polyunsaturated FA (Chilliard et al., 1991). Our results are consistent with this trans isomer hypothesis, because the supplement form that increases most rumen biohydrogenation (BH) intermediates (oils) also induces the greatest decreases in milk C6 to $\mathrm{C} 12$ percentage. The decrease in milk $\mathrm{C} 4$ to $\mathrm{C} 16$ yield was compensated for by an increase in $\mathrm{C} 18$ yield, resulting in a globally weak or nonsignificant effect on milk fat content.

Although the main putative inhibitors of de novo synthesis $(t 10 c 12-, c 10 t 12-$, and $t 9 c 11-18: 2)$ are mainly intermediates of $18: 2 \mathrm{n}-6 \mathrm{BH}$, the present results (Table 6) show that, on C6 to C14, lipid sources rich in 18:3n-3 given as oils induced similar responses to sources rich in 18:2n-6, whereas 18:3n-3 given as seeds were less inhibitory. Supplements rich in 18:3 provided as oils may thus also produce trans isomer inhibitors of de novo synthesis, or favor the rumen production of trans isomers from the dietary 18:2. On the percentage of 16:0, however, 18:2 was more inhibitory than 18:3 (probably through the inhibition of de novo-synthesized 16:0). A greater inhibiting effect of oils compared with seeds on C6 to C12 was thus observed for supplements rich in 18:3 (see Table 2 and, for 18:3 intake, Table 6), consistent with the greater percentage of rumen $\mathrm{BH}$ intermediates with oils. However, there were no significant effects of lipid protection, which might have been expected to produce fewer $\mathrm{BH}$ intermediates than the other forms. Protection was thus probably only partial, even with formaldehyde. This difference between oils and seeds tended to be less pronounced for $\mathrm{C} 14$ and $\mathrm{C} 16 \mathrm{FA}$.

The effect on odd-chain FA was similar to that observed on even-chain FA, arguing for a regulation of the secretion of these FA mainly at the mammary rather than the ruminal level, whereas the effect on branchedchain FA was nonsignificant on the few available data. 
Trans-16:1 percentage was not significantly affected, possibly because of its ruminal origin, whereas cis-16:1, probably arising from mammary $\Delta^{9}$-desaturation of 16:0, was inhibited, like 16:0, by most of the supplements.

Total C18 and 18:0. All 3 approaches to the database yielded a consistent view of the effect of oilseed lipid supplements on the percentage of total C18 FA: their percentages were increased by all the supplements, quadratically according to added lipid. The extent of the variations, from $35 \%$ of total FA with unsupplemented diets to 45 to $58 \%$ with lipid-supplemented diets, confirms the high plasticity of milk fat composition. This increase resulted from a decrease in milk $\mathrm{C} 4$ to $\mathrm{C} 16$ yield and an increase in $\mathrm{C} 18$ yield (data not shown). The quadratic component may come from the strong decrease in de novo synthesis for large amounts of supplements, which may limit the incorporation of C18 FA in milk lipids through effects on triglyceride synthesis (Glasser et al., 2007, 2008a).

There were few differences between supplements regarding the induced increase in 18:0 percentage, except that linseed induced a maximum increase at approximately $700 \mathrm{~g}$ of supplemental lipid, and a smaller increase above this amount. This did not appear in the interexperiment approach (Table 2 and Table 3), but is consistent with the greater increase in milk 18:0 percentage by 18:2 intake compared with 18:3 intake (Table 6 ). This is also consistent with the greater complete $\mathrm{BH}$ of 18:2 than 18:3 observed during in vitro incubations in rumen fluid (Jouany et al., 2007). In experiments that compared different lipid sources without a control diet (which were thus not included in the models), some workers have confirmed this observation (Kelly et al., 1998; Petit, 2003, 2004; Loor et al., 2005b), but others do not report any significant difference between 18:2and 18:3-rich lipids on milk 18:0 percentage (Chouinard et al., 1998; Petit, 2002; Ward et al., 2002; Brzoska, 2005).

Isomers of 18:1. In the interexperiment approach (Table 2 and Table 3), the sums of cis- and trans-18:1 were increased significantly by almost all the supplements. The same was true in the within-experiment responses to the supplements, which were linear for cis- and trans-18:1, but with some differences between supplement forms. This supplement form effect was, however, not found in the subset of data used for responses to 18:2 and 18:3 intakes from all lipid sources.

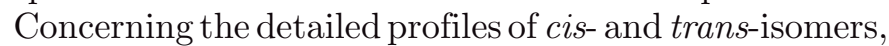
few data were available in the data set obtained with our selection criteria, despite the numerous questions regarding the nutritional properties of these FA. More data should be available in the next several years.
Isomers of 18:2. When total 18:2 was considered, protection of lipids greatly improved the milk 18:2 content, whereas seed and oil supplements had only moderate effects or none at all. This confirms the high rumen $\mathrm{BH}$ of dietary 18:2 observed for oils and seeds (Glasser et al., 2008b). Overall, the responses of milk $c 9 c 12-18: 2$ were very low, expressed according to either the supplements or the intake of $c 9 c 12-18: 2$ (even nonsignificant for 18:2 intake as oil), except for soybeans as seeds. The 2 most often reported isomers were $c 9 c 12-18: 2$ and $c 9 t 11-18: 2$ or total CLA. However, $c 9 t 11-18: 2$ makes up a large proportion of total CLA, representing, on average, $79 \%$ of total CLA in 25 treatments from recent reports with at least 8 different CLA isomers reported (Piperova et al., 2002; Secchiari et al., 2003; Shingfield et al., 2003, 2005; Loor et al., 2005a,b; Saebo et al., 2005). All studies that have evaluated the contribution of mammary desaturation of t11-18:1 to the secretion of $c 9 t 11-18: 2$ conclude that mammary desaturation was the major source of milk $c 9 t 11-18: 2$ (60 to $98 \%$, Griinari et al., 2000; see reviews in Shingfield et al., 2007; Glasser et al., 2008a). Milk c9t11-18:2 (and thus total CLA) was thus increased as expected by the supplements that increased milk $t 11-18: 1$. Most data on nonconjugated isomers other than $c 9 c 12$ were obtained for linseed supplements, for which only $c 9 t 13-$ and t11c15-18:2 were significantly increased. This difference between rapeseed and soybeans is consistent with $c 9 t 13-18: 2$ being a mammary desaturation product of ruminally produced $t 13-18: 1$ (Roy et al., 2006; Glasser et al., 2007), which is, like $t 11 c 15-18: 2$, an intermediate of 18:3n-3 rumen $\mathrm{BH}$. The importance of this last $\mathrm{BH}$ intermediate is illustrated by the mean percentage of $t 11 c 15-18: 2$ observed with linseed oil-supplemented diets $(2.2 \%$ of total FA), which was similar to that of c9c12-18:2 (2.4\%).

Percentage of 18:3. The increase in milk 18:3 percentage was also very limited in absolute amount, except with protected supplements. Without protection, mean percentage in milk hardly reached $1.2 \%$ of total FA, compared with $0.67 \%$ for unsupplemented diets. For 18:2, only protection with formaldehyde seemed to protect dietary 18:3 somewhat from extensive rumen BH. Compared with basal levels, however, the increase in 18:3 percentage can be significant.

\section{Modulation by Other Factors}

As already mentioned, the study of interfering factors was made complicated by the small number of available data when one or several selection criteria were applied to the original data set. The study of different supplement forms within the 3 categories (oils, seeds, and protected) exhibited only limited effects. With linseed, 
FA from whole seeds tended to be more completely hydrogenated than FA from treated seeds, to produce fewer intermediates, and to inhibit mammary de novo FA synthesis less. Calcium salts of rapeseed FA slightly increased milk cis-18:1 compared with oils, whereas no effect was observed with soybean Ca salts compared with soybean oils. This is consistent with the greater dissociation of more unsaturated FA salts in the rumen (Sukhija and Palmquist, 1990). The effects of the forage component of the diet and lactation stage were inconsistent across supplements and according to which milk FA was considered. For these effects, the results of experiments specifically designed to study them appear soundest. With the current metadesign, the study of modulating factors from an interexperiment point of view is limited by the available data and numerous interfering factors, and does not add any further insight compared with standard reviews (e.g., Chilliard and Ferlay, 2004; Dewhurst et al., 2006; Chilliard et al., 2007).

\section{CONCLUSIONS}

This work is the first to provide mean milk FA percentages and to quantify their responses to oilseed supplements from all available published data. Despite the large number of experiments on dietary oilseed lipid supplementation, the integration of all these published results was difficult because of heterogeneity in the data reported, either in the description of the diets and supplements, or in the milk FA composition and the factors studied (nature and treatments of lipid sources, basal diets, etc.)

However, taken together, these results confirm the high plasticity of milk FA composition, with the greatest variations being observed in the percentages of medium-chain versus $\mathrm{C} 18 \mathrm{FA}$, and among the $\mathrm{C} 18$ on 18:0, cis-18:1, and trans-18:1. The percentages of the polyunsaturated FA $c 9 c 12-18: 2$ and 18:3 were less variable, except when protected lipids (mostly formaldehyde treated) were provided. However, trans-18:1 and polyunsaturated FA exhibited the greatest variations when expressed relative to their respective basal levels (with unsupplemented diets). Oils, compared with seeds, induced greater percentages of trans-18:1 and tended to decrease C6 to C12 FA more. Intakes of 18:2and 18:3-rich lipid sources did not differ greatly in their effects on short- and medium-chain FA percentages and trans-18:1 percentage, although the profiles of individual 18:1 and 18:2 isomers in milk differed. With linseed oil supplements, $c 9 t 11$ - and $t 11 c 15-18: 2$ could reach levels comparable with that of $c 9 c 12-18: 2$. If additional studies with sufficient data to ensure comparison between experiments (FA intakes, amounts, and composition of the lipid supplements) and detailed milk FA profiles are published in the years to come, it will be possible to carry out further work on the response of individual isomers to lipid supplements, and add new FA of interest for studies on human nutrition and health.

\section{REFERENCES}

Bartsch, B. D., N. J. S. Ellis, D. M. McLean, and J. C. Radcliffe. 1976. Production, composition, and manufacturing properties of milk from grazing cows fed on a formaldehyde-treated sunflower seed supplement. Aust. J. Agric. Res. 27:917-927.

Bauman, D. E., and J. M. Griinari. 2001. Regulation and nutritional manipulation of milk fat: Low-fat milk syndrome. Livest. Prod. Sci. 70:15-29.

Bobe, G., G. L. Lindberg, A. E. Freeman, and D. C. Beitz. 2007. Short communication: Composition of milk protein and milk fatty acids is stable for cows differing in genetic merit for milk production. J. Dairy Sci. 90:3955-3960.

Brzoska, F. 2005. Effect of dietary vegetable oils on milk yield, composition and CLA isomer profile in milk from dairy cows. J. Anim. Feed Sci. 14:445-459.

Chilliard, Y., and A. Ferlay. 2004. Dietary lipids and forages interactions on cow and goat milk fatty acid composition and sensory properties. Reprod. Nutr. Dev. 44:467-492.

Chilliard, Y., A. Ferlay, R. J. Mansbridge, and M. Doreau. 2000. Ruminant milk fat plasticity: Nutritional control of saturated, polyunsaturated, trans and conjugated fatty acids. Ann. Zootech. 49:181-205.

Chilliard, Y., G. Gagliostro, J. Flechet, J. Lefaivre, and I. Sebastian. 1991. Duodenal rapeseed oil infusion in early and midlactation cows. 5. Milk fatty acids and adipose tissue lipogenic activities. J. Dairy Sci. 74:1844-1854.

Chilliard, Y., F. Glasser, A. Ferlay, L. Bernard, J. Rouel, and M. Doreau. 2007. Diet, rumen biohydrogenation and nutritional quality of cow and goat milk fat. Eur. J. Lipid Sci. Technol. 109:828-855.

Chouinard, P. Y., V. Girard, and G. J. Brisson. 1998. Fatty acid profile and physical properties of milk fat from cows fed calcium salts of fatty acids with varying unsaturation. J. Dairy Sci. 81:471-481.

Clapperton, J. L. 1982. The effect of sunflower oil on the fatty acid composition of the milk of cows fed either a fat-depressing diet or grass silage. J. Sci. Food Agric. 33:741-753.

Dewhurst, R. J., K. J. Shingfield, M. R. F. Lee, and N. D. Scollan. 2006. Increasing the concentrations of beneficial polyunsaturated fatty acids in milk produced by dairy cows in high-forage systems. Anim. Feed Sci. Technol. 131:168-206.

Fearon, A. M., C. S. Mayne, J. A. M. Beattie, and D. W. Bruce. 2004. Effect of level of oil inclusion in the diet of dairy cows at pasture on animal performance and milk composition and properties. J. Sci. Food Agric. 84:497-504.

Glasser, F., M. Doreau, A. Ferlay, J. Loor, and Y. Chilliard. 2007. Milk fatty acids: Mammary synthesis could limit transfer from duodenum in cows. Eur. J. Lipid Sci. Technol. 109:817-827.

Glasser, F., A. Ferlay, M. Doreau, P. Schmidely, D. Sauvant, and Y. Chilliard. 2008a. Long-chain fatty acid metabolism in dairy cows: A meta-analysis of milk fatty acid yield in relation to duodenal flows and de novo synthesis. J. Dairy Sci. 91:2771-2785.

Glasser, F., P. Schmidely, D. Sauvant, and M. Doreau. 2008b. Digestion of fatty acids in ruminants: A meta-analysis of flows and variation factors. 2. C18 fatty acids. Animal 2:691-704.

Goodridge, J., J. R. Ingalls, and G. H. Crow. 2001. Transfer of omega-3 linolenic acid and linoleic acid to milk fat from flaxseed or Linola protected with formaldehyde. Can. J. Anim. Sci. 81:525-532.

Griinari, J. M., B. A. Corl, S. H. Lacy, P. Y. Chouinard, K. V. V. Nurmela, and D. E. Bauman. 2000. Conjugated linoleic acid is synthesized endogenously in lactating dairy cows by delta 9-desaturase. J. Nutr. 130:2285-2291. 
Hermansen, J. E. 1995. Prediction of milk fatty acid profile in dairy cows fed dietary fat differing in fatty acid composition. J. Dairy Sci. 78:872-879.

Jouany, J. P., B. Lassalas, M. Doreau, and F. Glasser. 2007. Dynamic features of the rumen metabolism of linoleic acid, linolenic acid, and linseed oil measured in vitro. Lipids 42:351-360.

Kelly, M. L., J. R. Berry, D. A. Dwyer, J. M. Griinari, P. Y. Chouinard, M. E. Van Amburgh, and D. E. Bauman. 1998. Dietary fatty acid sources affect conjugated linoleic acid concentrations in milk from lactating dairy cows. J. Nutr. 128:881-885.

Loor, J. J., A. Ferlay, A. Ollier, M. Doreau, and Y. Chilliard. 2005a. Relationship among trans and conjugated fatty acids and bovine milk fat yield due to dietary concentrate and linseed oil. J. Dairy Sci. 88:726-740.

Loor, J. J., A. Ferlay, A. Ollier, K. Ueda, M. Doreau, and Y. Chilliard. 2005b. High-concentrate diets and polyunsaturated oils alter trans and conjugated isomers in bovine rumen, blood, and milk. J. Dairy Sci. 88:3986-3999.

Moate, P. J., W. Chalupa, R. C. Boston, and I. J. Lean. 2007. Milk fatty acids. I. Variation in the concentration of individual fatty acids in bovine milk. J. Dairy Sci. 90:4730-4739.

Nowak, W., and A. Potkanski. 2000. The effect of rolled rape seeds on milk composition and lactational responses. J. Anim. Feed Sci. 9:425-434.

Palmquist, D. L., A. D. Beaulieu, and D. M. Barbano. 1993. Feed and animal factors influencing milk fat composition. J. Dairy Sci. $76: 1753-1771$

Petit, H. V. 2002. Digestion, milk production, milk composition, and blood composition of dairy cows fed whole flaxseed. J. Dairy Sci. 85:1482-1490.

Petit, H. V. 2003. Digestion, milk production, milk composition, and blood composition of dairy cows fed formaldehyde treated flaxseed or sunflower seed. J. Dairy Sci. 86:2637-2646.

Petit, H. V., C. Germiquet, and D. Lebel. 2004. Effect of feeding whole, unprocessed sunflower seeds and flaxseed on milk production, milk composition, and prostaglandin secretion in dairy cows. J. Dairy Sci. 87:3889-3898.

Piperova, L. S., J. Sampugna, B. B. Teter, K. F. Kalscheur, M. P. Yurawecz, Y. Ku, K. M. Morehouse, and R. A. Erdman. 2002. Duodenal and milk trans octadecenoic acid and conjugated linoleic acid (CLA) isomers indicate that postabsorptive synthesis is the predominant source of cis-9-containing CLA in lactating dairy cows. J. Nutr. 132:1235-1241.

Roy, A., A. Ferlay, K. J. Shingfield, and Y. Chilliard. 2006. Examination of the persistency of milk fatty acid composition responses to plant oils in cows given different basal diets, with particular emphasis on trans-C18:1 fatty acids and isomers of conjugated linoleic acid. Anim. Sci. 82:479-492.

Saebo, A., P. C. Saebo, J. M. Griinari, and K. J. Shingfield. 2005. Effect of abomasal infusions of geometric isomers of 10,12 conjugated synthesis linoleic acid on milk fat in dairy cows. Lipids 40:823-832.

Secchiari, P., M. Antongiovanni, M. Mele, A. Serra, A. Buccioni, G. Ferruzzi, F. Paoletti, and F. Petacchi. 2003. Effect of kind of dietary fat on the quality of milk fat from Italian Friesian cows. Livest. Prod. Sci. 83:43-52.

Shingfield, K. J., S. Ahvenjarvi, V. Toivonen, A. Arola, K. V. V. Nurmela, P. Huhtanen, and J. M. Griinari. 2003. Effect of dietary fish oil on biohydrogenation of fatty acids and milk fatty acid content in cows. Anim. Sci. 77:165-179.

Shingfield, K. J., S. Ahvenjarvi, V. Toivonen, A. Vanhatalo, and P. Huhtanen. 2007. Transfer of absorbed cis-9, trans-11 conjugated linoleic acid into milk is biologically more efficient than endogenous synthesis from absorbed vaccenic acid in lactating cows. J. Nutr. 137:1154-1160.

Shingfield, K. J., and J. M. Griinari. 2007. Role of biohydrogenation intermediates in milk fat depression. Eur. J. Lipid Sci. Technol. 109:799-816.

Shingfield, K. J., C. K. Reynolds, B. Lupoli, V. Toivonen, M. P. Yurawecz, P. Delmonte, J. M. Griinari, A. S. Grandison, and D. E. Beever. 2005. Effect of forage type and proportion of concentrate in the diet on milk fatty acid composition in cows given sunflower oil and fish oil. Anim. Sci. 80:225-238.

St-Pierre, N. R. 2001. Invited review: Integrating quantitative findings from multiple studies using mixed model methodology. J. Dairy Sci. 84:741-755.

Sukhija, P. S., and D. L. Palmquist. 1990. Dissociation of calcium soaps of long-chain fatty acids in rumen fluid. J. Dairy Sci. 73:1784-1787.

Ward, A. T., K. M. Wittenberg, and R. Przybylski. 2002. Bovine milk fatty acid profiles produced by feeding diets containing solin, flax, and canola. J. Dairy Sci. 85:1191-1196. 